Article

\title{
Efficiency of Coupled Experimental-Numerical Predictive Analyses for Inter-Story Floors Under Non-Isolated Machine-Induced Vibrations
}

\author{
Enrico Bergamo $\mathbb{D}$, Marco Fasan $\mathbb{D}$ and Chiara Bedon * $\mathbb{D}$ \\ Department of Engineering and Architecture, University of Trieste, 34127 Trieste, Italy; \\ enrico.bergamo@me.com (E.B.); mfasan@units.it (M.F.) \\ * Correspondence: chiara.bedon@dia.units.it; Tel.: +39-040-558-3837
}

Received: 27 July 2020; Accepted: 14 September 2020; Published: 16 September 2020

check for updates

\begin{abstract}
Machine-induced vibrations represent, for several reasons, a crucial design issue for industrial buildings. At the early design stage, special attention is thus required for the static and dynamic performance assessment of the load-bearing members, given that they should optimally withstand ordinary design loads but also potentially severe machinery operations. The knowledge and reliable description of the input vibration source is a key step, similarly to a reliable description of the structural system, to verify. However, such a kind of detailing is often unavailable and results in a series of simplified calculation assumptions. In this paper, a case-study eyewear factory built in 2019 is investigated. Its layout takes the form of a two-story, two-span $(2 \times 14.6 \mathrm{~m})$ precast concrete frame (poor customer/designer communication on the final equipment resulted in various non-isolated computer numerical control (CNC) vertical machines mounted on the inter-story floor, that started to suffer from pronounced resonance issues. Following past experience, this paper investigates the validity of a coupled experimental-numerical method that could be used for efficient assessment predictive studies. Based on on-site experiments with Micro Electro-Mechanical Systems (MEMS) accelerometers mounted on the floor and on the machine (spindle included), the most unfavorable machine-induced vibration sources and operational conditions are first characterized. The experimental outcomes are thus used to derive a synthetized signal that is integrated in efficient one-bay finite element (FE) numerical model of the floor, in which the machine-structure interaction can be taken into account. The predictability of marked resonance issues is thus emphasized, with a focus on potential and possible limits of FE methods characterized by an increasing level of detailing and computational cost.
\end{abstract}

Keywords: vibration serviceability; non-isolated computer numerical control (CNC) machines; precast concrete inter-story floor; on-site dynamic experiments; finite element (FE) numerical modeling

\section{Introduction}

\subsection{Research Topic}

The vibration serviceability assessment of civil engineering facilities represents a challenging issue for the design of both new structures and existing systems to retrofit [1]. Often, however, such a verification stage is not assessed with careful consideration. In some other cases, the lack of reliable design criteria or reference input data in support of designers make this step even more uncertain. Numerical methods and tools, in this regard, can notoriously offer strong support to designers. A multitude of combinations of loads can be efficiently assessed at the early design stage of buildings and infrastructural systems, so as to prevent potential unfavorable operational conditions. 
Industrial buildings, in particular, can be extremely vulnerable to vibrations, especially in presence of heavy machines, or even a combination of heavy machines and unsafe design choices. As such, dedicated studies and calculation methods are generally required for them [2,3], and various research studies can also be found in the literature, for several industrial applications [3-6]. In the specific case of industrial floors and severe machine-induced vibrations, the knowledge of the input vibration source and the machinery characterization, as well as its dynamic interaction with the primary structure, represent key influencing parameter for an accurate machine-structure coupled analysis.

From a mechanical point of view, it is obvious that vibrating machines should be mounted on the ground floor, on a rigid foundation system $[7,8]$, in the same way that a multitude of configurations of technical interest can be found in the literature, depending on the factory production. A turbine generator foundation was optimized in the cross-section of the load-bearing members in [9], under the effects of rotating machinery dynamic loads. Finite element (FE) numerical analyses and analytical studies are carried out based on a simplified description of the machinery features. The soil interaction with the machinery foundation was numerically explored in [10]. To study the influence of a rigid concrete foundation on the dynamic characteristics of a number of different heavy-duty CNC machines and different soil properties, an enhanced multibody transfer matrix system approach was presented in [11]. A numerical and analytical investigation is dedicated in [12] to the calculation of natural frequencies for machineries on soft foundations. It was proved that the both the size of the contact area between given machine feet and the foundation, as well as the stiffness of the foundation, can markedly modify the calculated frequencies. Besides, the extensive study in [12] (and others) lack experimental feedback, especially in terms of machinery features and characterization.

In the last few decades, several research studies have been focused on the experimental analysis of machines, especially for maintenance and manufacturing purposes $[13,14]$. The laboratory studies presented in [15] show that CNC machinery operations can be efficiently captured (in terms of induced signal magnitude and frequency content, under various working programs) with the support of an accelerometer mounted on the moving spindle. The experimental analysis in [15], however, is limited to the frequency analysis of the spindle movements and the substructure is disregarded. A similar study, based on vibration-meter acquisitions, is used in [16] for machinery diagnostics purposes. The experimental analysis presented in [17] shows that a single micro electro-mechanical systems (MEMS) sensor installed on a CNC machine can be efficiently used for monitoring activities, and thus for optimized production and maintenance goals. In [18], an active control system is proposed to minimize the machine-induced vibrations.

In general, it is thus recognized that field experimental monitoring activities for machineries can support their optimal serviceability. Once the machine-structure interaction needs also to be assessed, however, a series of additional, multiple influencing parameters should be properly taken into account for design calculations [19,20]. From a practical point of view, this requirement is often not satisfied, for several motivations (i.e., uncertainties on material properties, damping terms, foundation system detailing, machinery working programs, etc.). As such, a combination of unfavorable choices could result in discomfort for the occupants, but also unsafe operational conditions for the mounted machines [21,22], noise [23], or structural troubles that should be prevented. When this design step is not properly assessed, even major efforts should be needed for retrofit and mitigation interventions [24-26], with the support of various monitoring techniques [27-29].

\subsection{Research Methods}

This paper investigates the potential of an improved coupled experimental-numerical approach for predictive vibration serviceability studies, by taking into account a case-study industrial building realized in Italy, to host an eyewear factory. The production of optical glasses is based on various CNC vertical machinery centers, as shown in Figure 1. At the time of the structural design, the poor communication between the customer and the designer about the final operational layout of the 
building equipment resulted in a number of non-isolated machines mounted on the inter-story floor, with consequent severe resonance issues and management troubles.

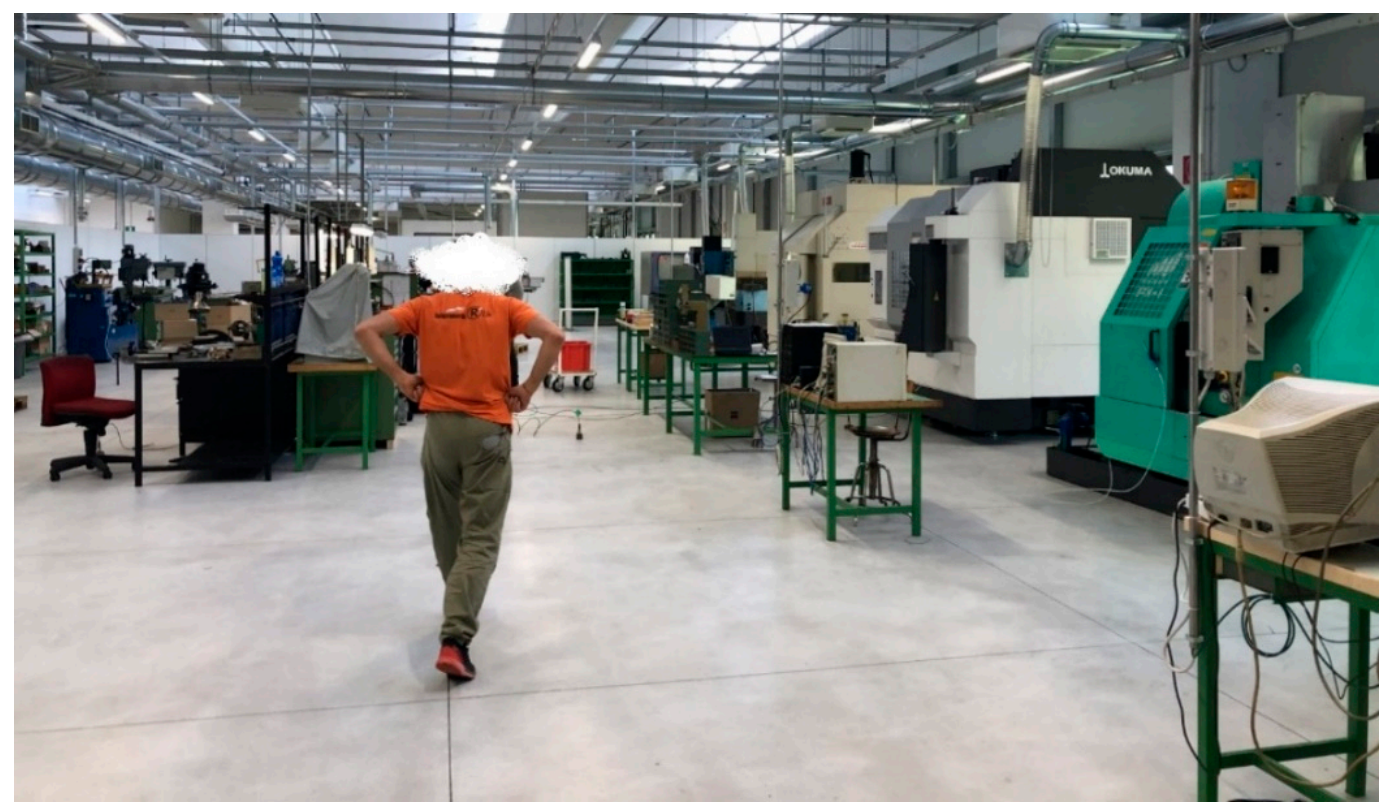

Figure 1. General view of the floor object of investigation, with evidence of CNC machines and equipment.

Based on those past events, an experimental, analytical, and finite element (FE) numerical investigation was carried out, as presented in this paper. The goal of this study is to assess the vibration issues of the primary structure (with a focus on its long-span inter-story floor), and to emphasize the reliability of various calculation tools for the machine-structure interaction analysis, in support of predictive studies that should be always carried out at the preliminary stage of the structural design process. As a reference, for comparative purposes, conventional recommendations for the analysis of floor vibrations are taken into account [2].

More in detail, a coupled experimental-numerical approach is presented and validated in this paper, with the support of a progressively increasing grade of modeling detailing for the structure, but also of dedicated experimental acquisitions with MEMS accelerometers. The validity of an efficient one-bay FE model of the inter-story floor, calibrated to the available experimental feedback, is discussed in this paper. Differing from past literature studies on machine-induced vibrations on rigid foundation systems (i.e., [9-12]), or focused on the machinery characterization only (i.e., [15-17]), the attention of the experimental analysis is in fact focused both on the movable components of the machines and on the corresponding response of the primary structure. Based on a dedicated experimental program, the final result takes the form of a synthetized signal for the CNC machine that can be used for refined numerical analyses of the primary system. Moreover, on the side of the primary structure, the refined calibration of other relevant FE input parameters (such as material properties and damping) can be further exploited from the available experimental data, with remarkable improvement of the FE dynamic predictions, compared to conventional assumptions [2].

To this aim, the reference methods and design prescriptions are first summarized in Section 2. Section 3 briefly describes the structural system object of study, while in Section 4 the attention is focused on the experimental characterization of the machinery activity, with the derivation of synthetized signals. Once the experimental analysis is extended to the floor (Section 5), the refined dynamic investigation is further supported by an efficient one-bay FE numerical model [30] that is used to predict the natural frequencies of the system (linear frequency analyses), as well as the expected dynamic amplification effects (DAF) due to the working machines (steady-state analyses 
with synthetized machinery signal). As shown, once the primary structure and the input vibration source are accurately described in their key features, the final result takes the form of a reliable coupled experimental-numerical design procedure that should be used to prevent unfavorable operational conditions. In doing so, the efficiency and possible limits of FE numerical assemblies characterized by a progressively increasing degree of accuracy (and thus computational cost) are also emphasized for the examined industrial floor.

\section{State-of-Art on Machine-Induced Floor Vibrations}

\subsection{Mathematical Problem}

For civil engineering applications, the prediction (and control, or mitigation) of unfavorable vibration phenomena is implicitly related to the serviceability checks that should be generally carried out at the early design stage. Both in the case of new or existing structures, it is necessary to dynamically characterize the load-bearing structure to verify, as well as to describe in detail any source of vibrations that could affect its behavior under operational conditions. In the case of inter-story floors, their vibration response mainly depends on a combination of masses, stiffness properties and damping of structural members, services, etc. As such, knowledge is required for their (i) geometry, (ii) boundary conditions, (iii) characteristics of the materials in use (and in particular their modulus of elasticity (MoE)), as well as for the calibration of (iv) any source of damping, and (v) the distribution and magnitude of permanent loads (self-weight and superimposed dead loads) plus the accidental loads. When these floors are expected to carry heavy equipment, the machine-structure interaction should focus also on (vi) the magnitude and distribution of superimposed masses, but also (vii) the features of the vibration sources (magnitude, frequency content, etc.), given that they can be both responsible of severe modifications in the dynamic equilibrium and parameters of the empty floors [9-12]. Major effects due to unfavorable resonance effects could in fact significantly affect the workers' comfort, but also the integrity of the structural members. Moreover, machine-induced vibrations could transmit for long distances, thus to a huge number of load-bearing components.

According to literature [31], at the early design stage, all the above influencing parameters can be efficiently taken into account using simplified analytical methods and two-degree of freedom (2-DOF) calculations, or even more refined FE numerical analyses, with an increasingly computational effort in terms of modeling details and/or cost of simulations (i.e., frequency, transient or time history analyses), see for example [9-12].

Based on Figure 2a, the machine-structure interaction can be described in the form of two governing equations for the displacement of both the bodies under the imposed machine-induced force $F_{\mathrm{EQ}}[31]$

$$
\left\{\begin{array}{l}
u_{1}=\frac{\left(K_{1}+K_{2}-M_{2} \omega^{2}\right)}{\left(K_{1}-M_{1} \omega^{2}\right)\left(K_{1}+K_{2}-M_{2} \omega^{2}\right)-K_{1}^{2}} F_{\mathrm{EQ}} \sin (\omega t) \\
u_{2}=\frac{-K_{1}}{\left(K_{1}-M_{1} \omega^{2}\right)\left(K_{1}+K_{2}-M_{2} \omega^{2}\right)-K_{1}^{2}} F_{\mathrm{EQ}} \sin (\omega t)
\end{array}\right.
$$

where $F_{\mathrm{EQ}} \sin (w t)$ is the effect of the operating machinery tool, while $\omega$ represents the two possible frequency values at which the 2-DOF system would resonate, depending on the involved mass $\left(M_{1}, M_{2}\right)$, stiffness $\left(K_{1}, K_{2}\right)$ and damping $\left(C_{1}, C_{2}\right)$ contributions. As such, a simple approach to estimate the resonance frequencies and the transmissibility magnitude for the machine-induced effects to the floor is given by

$$
T=\left|\frac{-K_{1} K_{2}}{\left(K_{1}-M_{1} \omega^{2}\right)\left(K_{1}+K_{2}-M_{2} \omega^{2}\right)-K_{1}^{2}}\right|
$$

When the machine is rigidly restrained on the floor $\left(K_{1} \rightarrow \infty\right)$, the mathematical model in Figure 2a reduces to a single DOF that transfers all the vibration source and machinery power to the structure. Depending on the damping and frequency properties of the involved systems, see Figure $2 b$, 
the machine-structure frequency ratio should be possibly limited to a maximum of 0.5 , or to a value higher than 1.3 , in order to minimize the dynamic amplification phenomena.

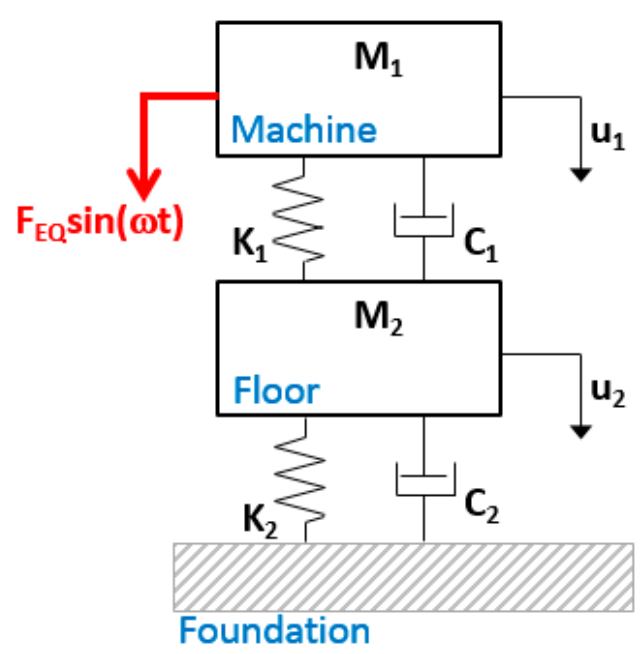

(a)

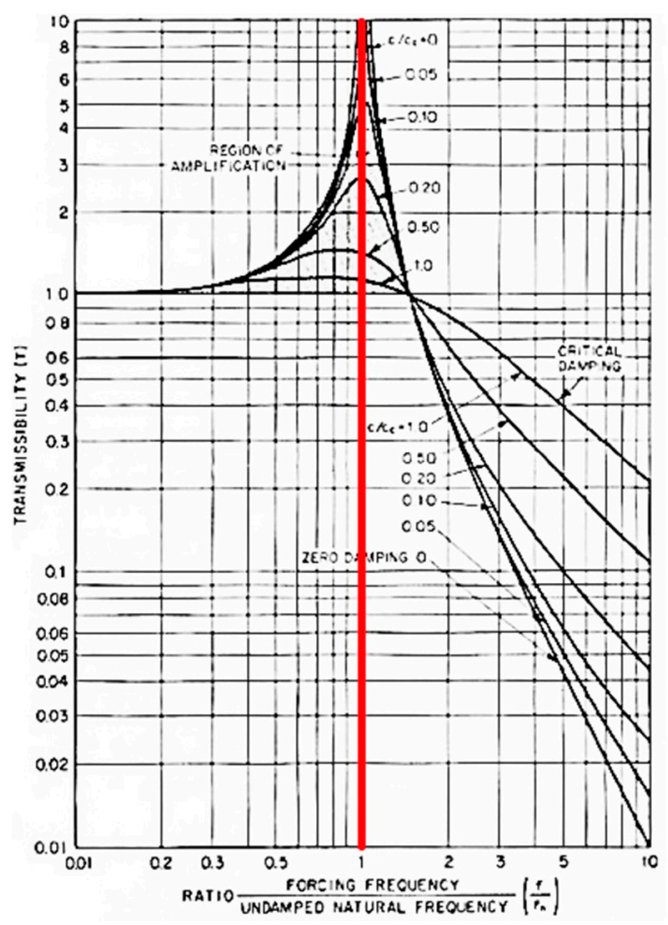

(b)

Figure 2. Reference methods for the analysis of machine-structure interaction phenomena: (a) 2-DOF model and (b) transmissibility of the machine force.

To properly assess such a dynamic issue, knowledge is thus basically required on the side of the machine (i.e., for its reliable characterization under operating or non-operating conditions) but also on the side of the floor/structure object of study, that should be properly described. In this case, the efficiency maximization of FE tools should be supported by reliable schematization approaches. Large floors under static loads (i.e., Figure 3) are for example commonly analyzed on the base of a given efficient width $b_{\text {eff }}$ that captures the behavior of the structure. Among others, one of its conventional definitions takes the form of

$$
b_{\text {eff }}=2 L_{\mathrm{y}} \sqrt[4]{\frac{D_{11}}{D_{22}}} \leq \frac{2}{3} L_{\mathrm{x}}
$$

with $L_{\mathrm{x}}, L_{\mathrm{y}}$ the dimensions in Figure 3 and $D_{11}, D_{22}$ the bending stiffnesses (per unit of width) in the $x$, $y$ directions respectively (with $x$ denoting the girders direction and $y$ the joists).

The research study summarized in [32] proved that the analysis of limited regions for flexible floors (under walking conditions) can affect the corresponding dynamic estimates, and thus the correctness of FE simulations, especially with regard to the expected magnitude of resonance phenomena (i.e., dynamic amplification factor, DAF [31]) and the contribution of the torsional rigidity of the floor, $D_{\mathrm{t}}$ (when relevant).

A series of design recommendations was thus provided in [32], to prevent possible unreliable dynamic numerical predictions. A similar effect can be expected also for floors under machine-induced vibrations. 


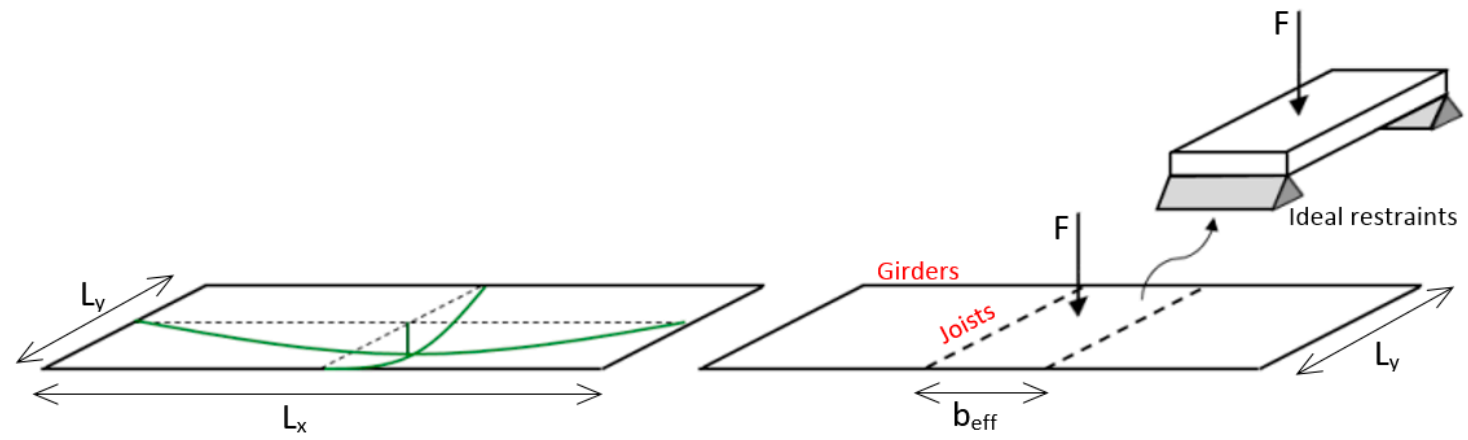

Figure 3. Efficient width approach for the analysis of long floors. Adapted from [32] under the terms and condition of CC BY-NC 4.0 license.

Depending on the detailing of joists, girders, and slab, in this regard, the structural behavior of a given floor takes the form of a variably stiffened plate [33-36]. When the dynamic behavior of the floor in Figure 3 is mostly governed by a 'joist panel model' vibration (i.e., with a fundamental natural frequency that is close to the frequency of the joists in bending about their major axis), Equation (3) can be taken into account for preliminary estimates, thus operating on a $b_{\text {eff }} \times L_{\mathrm{y}}$ equivalent module.

However, in the presence of adjacent bays, Equation (3) should be properly adapted and integrated with additional terms (with up to a 100\% increase), in order to include the participation of a more extended floor region in the fundamental vibration mode of the system [37]. Depending on the structural concept and detailing of the floor, a possible 'girder panel mode' (i.e., governed by the vibration response of the girders) could be also relevant. Finally, when a 'combined' fundamental vibration mode is expected for the floor object of study, its sensitivity to the flexibility of the supporting joists and girders should be further taken into account.

\subsection{Reference Design Stantards}

Besides the availability of several tools, the topic is not well addressed by the available design standards for structures, and thus even underrated by structural designers. For example, the general recommendation of the existing Eurocodes is to supply lower limits for the natural fundamental frequency of floors, depending on their prevailing constructional material [38]. Such a requirement, however, is still limited to human comfort assessment, and does not apply to floors with working machines. The Italian NTC2018 standard [39,40], in this regard, takes inspiration from [38] and recommends that -in case of floors with a fundamental vibration frequency lower or equal than $5 \mathrm{~Hz}$ - "specific calculation methods" should be adopted to avoid vibration issues for the comfort of occupants. Such an approach follows the basic assumption that humans are mostly sensitive to vibrations in the range of $4-8 \mathrm{~Hz}$ [41]. Accordingly, appropriate countermeasures should be taken for the design.

In the case of industrial floors with machines, major issues for structural designers can derive from the lack of any kind of detailing about the machine-structure interaction assessment (i.e., Figure 2). Sometimes, the structural designer is aware of the final destination of the building (i.e., equipment features and final layout). Moreover, it is possible that the machinery manufacturers do not provide detailed input data about the machinery activities, and thus the consequent quantification of the vibration source. Finally, it is recognized that simplified calculation methods are not able to capture the real dynamic phenomena of machine-induced vibrations.

The UNI9916 standard [42], in this regard, focuses on the susceptibility of structures to experience any damage due to vibrations, based on the limitation of the velocity peak that is expected under operational conditions. The recommended limits are derived and adapted from [43]. For industrial floors with a fundamental natural frequency not higher than $10 \mathrm{~Hz}$, the velocity peak is limited to a maximum of $20 \mathrm{~mm} / \mathrm{s}$ for short-term vibrations, see Figure 4 . 


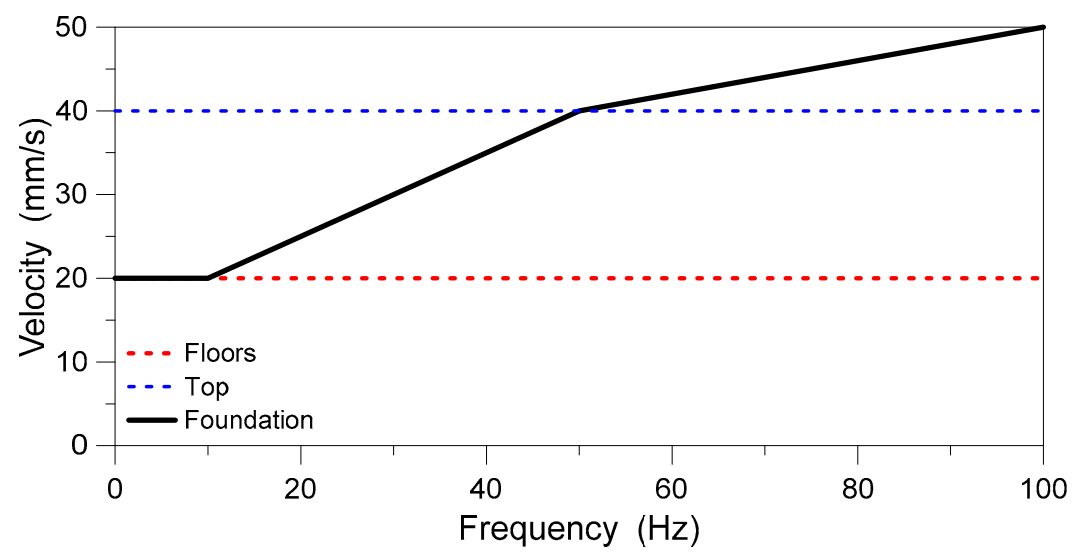

Figure 4. Velocity peak limits to prevent structural damage in industrial buildings exposed to short-term vibrations.

\section{Case-Study Building}

\subsection{Design Concept}

The examined factory is located in Northern Italy and has been constructed during 2019. All the load-bearing components are designed in accordance with the National regulations for seismic-resistant structures $[39,40]$.

The two-story, two-span, precast concrete is characterized by $13 \mathrm{~m}$ of elevation, with plan dimensions of $L_{x}=67.1 \times L_{y}=30.8 \mathrm{~m}$ and an aspect ratio $\alpha=L_{x} / L_{y}=2.17$ (Figure 5). The grid of beams and columns schematized in Figure 5 detects $6 \times 2$ adjacent bays (with $l_{\mathrm{x}}=11 \times l_{\mathrm{y}}=14.9 \mathrm{~m}, \alpha=0.74$, for each one of them). Based on earlier observations and client requirements, the research study was focused on the single-span region in evidence. The structural concept, more in detail, includes a series of plinth-restrained, square columns $(80 \times 80 \mathrm{~cm}$ the cross-section) and prestressed, precast beams, that are used in the $x$ direction to support the inter-story floor ( $+8 \mathrm{~m}$ from the foundation) and the wing-shaped members of the roof (+13 $\mathrm{m}$ from the foundation). All the beams have cross-section features that agree with Figure $5 \mathrm{~b}$, and cover a total span of $10.25 \mathrm{~m}$, with $0.2 \mathrm{~m}$ the width of cantilever supports that are offered by the columns.

\subsection{Inter-Story Floor}

The floor schematized in Figure 5a consists of a series of adjacent, unconnected double tee modular units and a continuous, cast-in-situ concrete slab on their top, that ensures the structural continuity and a certain flexural/torsional rigidity for the diaphragm. Depending on their final position, the double tee elements have cross-section features that agree with Figure 6. The nominal height is set in $h=0.8 \mathrm{~m}$, while the width $B$ is generally equal to $2.34 \mathrm{~m}, 2.50 \mathrm{~m}$ or $2.55 \mathrm{~m}$. The distance of the webs $(b=1.3 \mathrm{~m})$ and the thickness of the top cap ( $h_{\text {cap }}=0.05 \mathrm{~m}$ ) are kept fix.

The double tee elements are characterized by high slenderness, given that they are simply supported over a total span $L=14.62 \mathrm{~m}$ (with $14.22 \mathrm{~m}$ the actual bending span, due to the presence of restraints). The width-to-span aspect ratio of a single module is thus calculated in the order of $\alpha=0.18$. The end supports are realized in the form of tee beams (type \#1 and \#2, according to Figure $5 b$ ), that offer a continuous $0.2 \mathrm{~m}$ wide base restraint to the webs. Along the span, see Figure $6 \mathrm{~b}$, these elements are characterized by an initial upward bow $\left(u_{0}=0.04 \mathrm{~m}=L / 365\right.$ its maximum amplitude at the mid-span section). According to the initial bow of the precast elements, the cast-in-situ concrete slab has a nominal thickness $h_{\text {slab }}$ comprised between $0.11 \mathrm{~m}$ (at mid-span) and $0.15 \mathrm{~m}$ (in the region of the end supports). The total mass of a typical modular unit is thus calculated in (with top slab included)

$$
M_{\text {module }}=M_{\mathrm{TT}}+M_{\text {slab }}=14.6+11.3 \approx 25.9 \text { ton }
$$




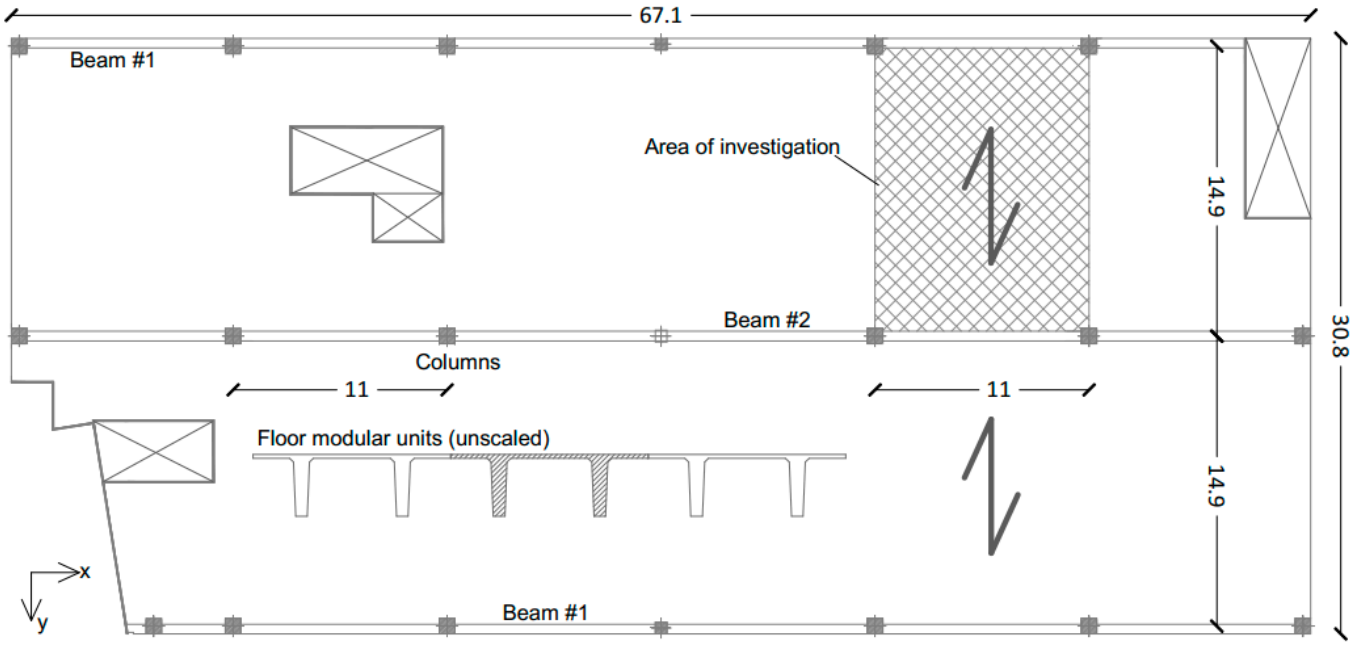

(a)
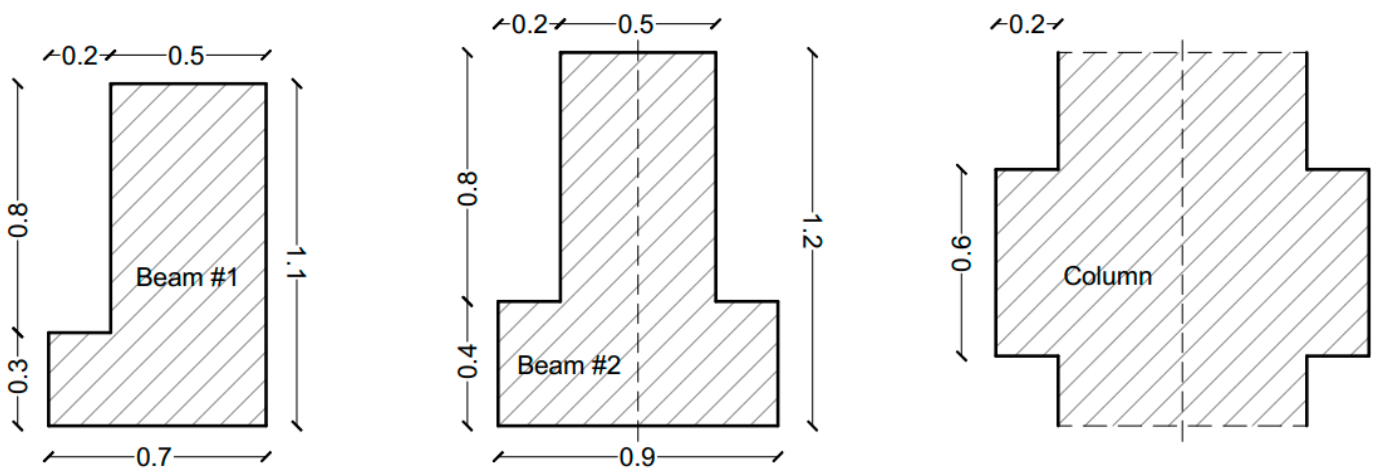

(b)

Figure 5. Case-study building: (a) plan view of the inter-story floor, with (b) cross-sectional details of the precast concrete beams and columns (nominal dimensions in $\mathrm{m}$ ).

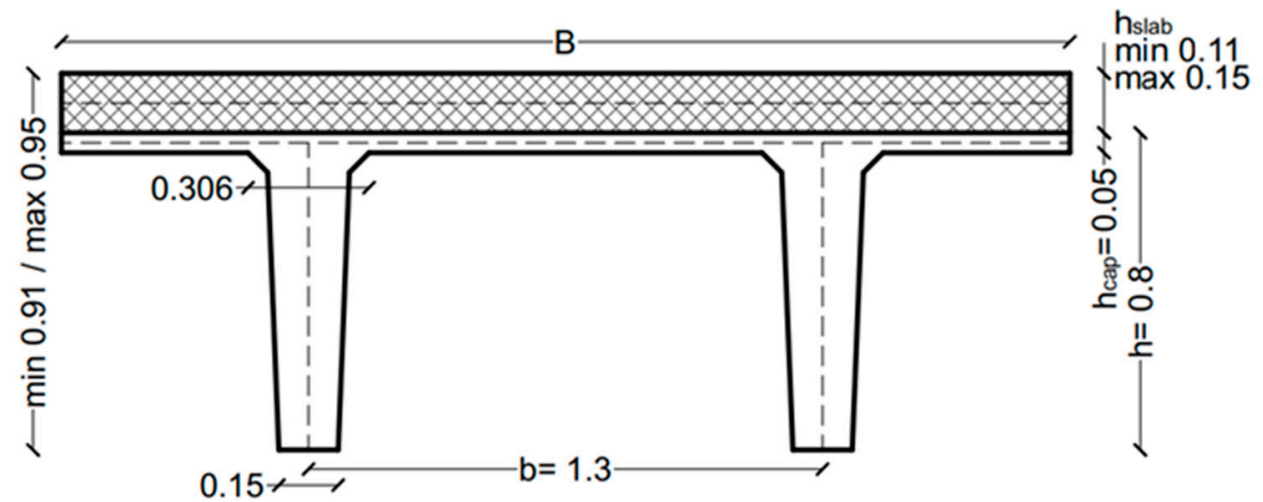

(a)

Figure 6. Cont. 


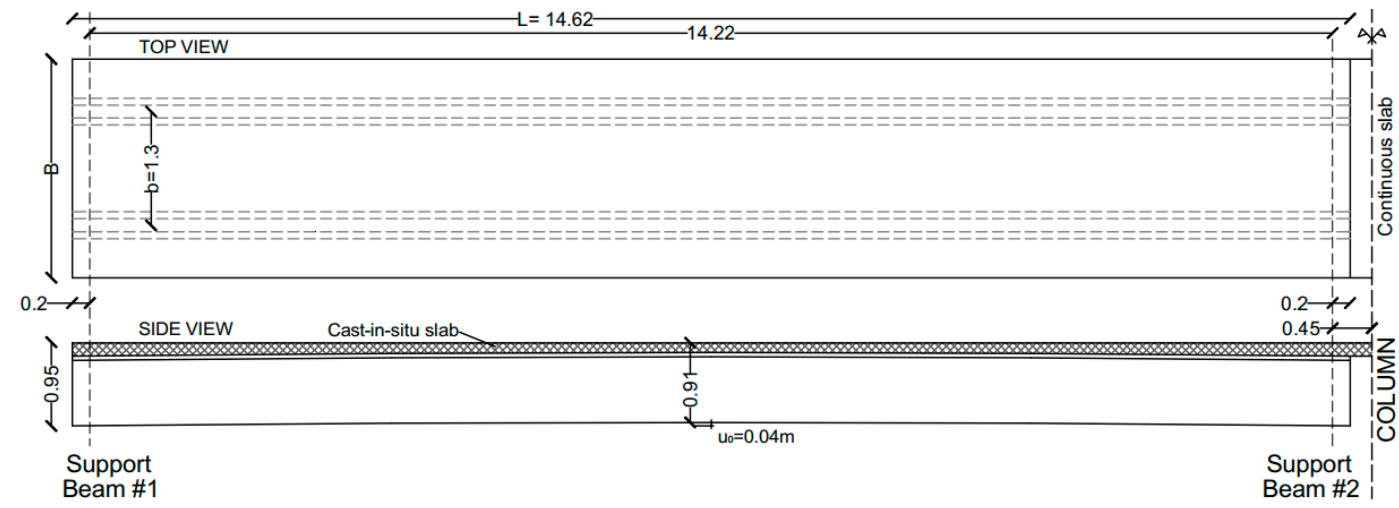

(b)

Figure 6. Reference modular unit for the inter-story floor under investigation: (a) transversal cross-section and (b) plan/side views of a single module (nominal dimensions in $\mathrm{m}$ ).

The geometrical and inertial properties for the double tee section in Figure 6, as well as for the slab and the supporting beams is summarized in Table 1.

The second moments are referred to the element, where $I_{\max }$ and $I_{\min }$ are calculated for each section, while $A$ is the cross-section and $I_{\mathrm{t}}$ the moment of inertia.

Table 1. Reference section properties.

\begin{tabular}{ccccc}
\hline \multirow{2}{*}{ Element } & \multicolumn{4}{c}{ Section Parameter } \\
\cline { 2 - 5 } & $\left.\boldsymbol{A} \mathbf{( m}^{\mathbf{2}}\right)$ & $\boldsymbol{I}_{\max }\left(\mathbf{m}^{\mathbf{4}}\right)$ & $\boldsymbol{I}_{\min }\left(\mathbf{m}^{\mathbf{4}}\right)$ & $\boldsymbol{I}_{\mathbf{t}}\left(\mathbf{m}^{\mathbf{4}}\right)$ \\
\hline Slab $(\max , B=2.5 \mathrm{~m})$ & 0.373 & 0.1953 & 0.0070 & 0.0027 \\
Slab $(\min , B=2.5 \mathrm{~m})$ & 0.275 & 0.1432 & 0.0027 & 0.0010 \\
Double tee module $(B=2.5 \mathrm{~m})$ & 0.392 & 0.1578 & 0.0254 & 0.0017 \\
Beam \#1 & 0.076 & 0.0645 & 0.0182 & 0.0373 \\
Beam \#2 & 0.061 & 0.0943 & 0.0326 & 0.0507 \\
\hline
\end{tabular}

\subsection{Materials}

As usual, the steel reinforcement detailing for the load-bearing members of interest was disregarded in this study. On the other side, the nominal material properties for the concrete mixtures were derived from the available technical documentation, see Table 2.

Table 2. Reference mechanical properties for the concrete types in use (nominal and experimental values)

\begin{tabular}{cccccc}
\hline \multirow{2}{*}{ Mix } & \multirow{2}{*}{ Element } & \multicolumn{2}{c}{ Nominal } & \multicolumn{2}{c}{ Experimental (avg.) } \\
\cline { 3 - 6 } & & Grade & $E_{\text {cm }}(\mathbf{M P a})$ & $f_{\text {ck }}$ (MPa) & $E_{\text {cm }}(\mathbf{M P a})$ \\
\hline Cast-in-situ concrete & Continuous slab & C25/30 & 31,476 & 53.3 & 37,893 \\
Precast concrete & $\begin{array}{c}\text { Columns, beams, } \\
\text { double tee floor modular units }\end{array}$ & C50/67 & 38,214 & 76.1 & 41,674 \\
\hline
\end{tabular}

At the time of the building construction, however, the compressive tests carried out on a total of 32 concrete cubes resulted in a relatively higher mean compressive resistance $f_{\mathrm{cm}}$ for both the concrete types (up to $+20 \%$ and $+9 \%$ for the cast-in-situ and precast respectively, compared to their nominal grade in Table 2), and thus in a relevant modification of the actual static MoE values, given that [39]

$$
E_{\mathrm{cm}}=2200 \sqrt[3]{\frac{f_{\mathrm{cm}}}{10}}
$$


with $f_{\mathrm{ck}}$ the characteristic compressive strength given by

$$
f_{\mathrm{cm}}=\mathrm{f}_{\mathrm{ck}}+8
$$

\subsection{CNC Machines}

The floor region object of study is composed of five modular units (with $B=$ var) and hosts three non-isolated machines. The plan dimensions are schematized in Figure 7, with evidence of the OKUMA footprint and layout.

The equipment, more in detail, includes an OKUMA - GENOS M560-V-e vertical machinery tool [44] with total mass $M_{\mathrm{OKUMA}}=7700 \mathrm{~kg}$ (and $M_{\text {spindle }}=400 \mathrm{~kg}$ for the movable components) that roughly corresponds to $\approx M_{\text {module }} / 3$ (with $M_{\text {module }}$ given by Equation (1), with $B=2.38 \mathrm{~m}$ ). Additional superimposed permanent loads are represented by MATSUURA [45] and BRIDGEPORT [46] machines (their weights being $4500 \mathrm{~kg}$ and $2700 \mathrm{~kg}$ ) and their equipment $(\approx 150 \mathrm{~kg} /$ machine).

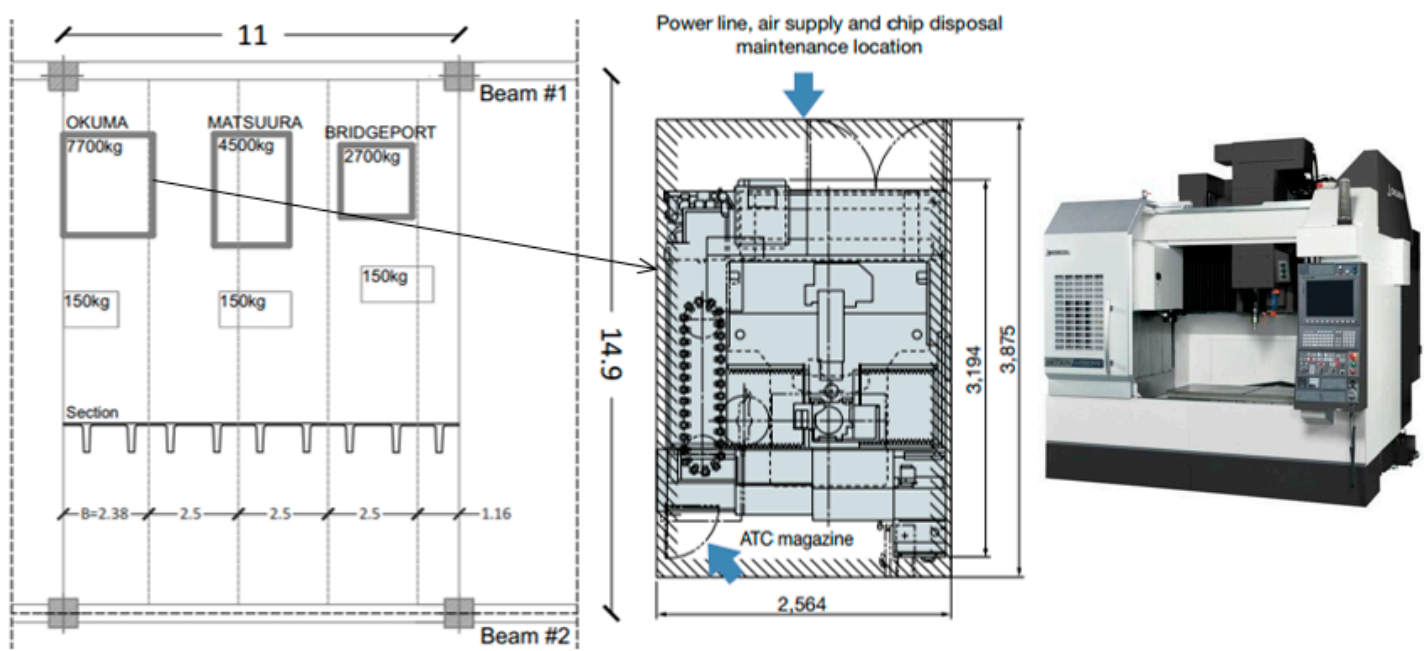

Figure 7. Plan view of the CNC machines on the floor region object of study (nominal dimensions in $\mathrm{m}$ ), with details of the OKUMA machinery center.

\section{Experimental Investigation}

A series of on-site dynamic experiments was carried out on the inter-story floor in October 2019, to assess its dynamic performance under the working CNC machines. The experimental investigation and research study herein presented took advantage of some marked vibration issues that the factory have revealed in its early stage activity. In total, accordingly, a set of 12 machinery/floor measurements were acquired from different configurations (i.e., by varying the reference machine, the assigned working process, the layout of instruments for the measurement of accelerations). Based also on the customer feedback, the majority of research efforts of the on-site tests was finally focused on the OKUMA machinery center and on the floor region directly affected by its activities.

\subsection{OKUMA Machinery Center}

At the time of building construction and equipment, eight rigid supports consisting of foundation washers with a base diameter of $120 \mathrm{~mm}$ were used to mount the OKUMA center on the floor (Figure 8a). Under the typical operational conditions for the factory object of study, the spindle and the movable components in Figure $8 \mathrm{~b}$ can be subjected to tri-axial displacements and cyclic accelerations that are directly transferred to the supporting floor, and thus should be properly accounted for the detailing and assessment of the primary load-bearing components. Certainly, such a kind of feedback about the machinery features and activity represents a key input parameter for structural designers. On the other side, like in the case-study herein described, this can be hard to characterize, and in some cases, 
basic nominal features are only available. According to some specifications by the manufacturer [44], for example, the spindle motor has a nominal power of $22 \mathrm{~kW}$. Depending on the working process, it can be set to operate in the range of frequencies from $1 \mathrm{~Hz}$ to $250 \mathrm{~Hz}$, with an allowable vertical travel of $460 \mathrm{~mm}$ (vertical (Z) direction), or $560 \mathrm{~mm}$ and $1050 \mathrm{~mm}$ in the horizontal (X, Y) directions. During the experimental program, careful attention was thus paid to capture and characterize the input vibration source of major interest for structural diagnostic purposes. Besides the availability of different monitoring techniques (i.e., [27-29]), such a goal was achieved with the support of a digital MEMS tri-axial accelerometer (ADXL355 type [47]) that was mounted on the movable spindle components in Figure $8 \mathrm{~b}$ (mp\#1 control point). The sampling rate of the accelerometer was set in $500 \mathrm{~Hz}$, and the typical experimental record was characterized by a minimum duration of 2 min of machinery activity, for each test repetition. A number of 17 acceleration records was collected for the vertical machinery operations. Additional feedback was made possible by coupled video-tracking acquisition techniques (Figure 8c [48]). Such a series of experimental records was properly combined by simultaneous acceleration acquisitions on at the base of the OKUMA machine, as well as on the floor (see Section 4.2).

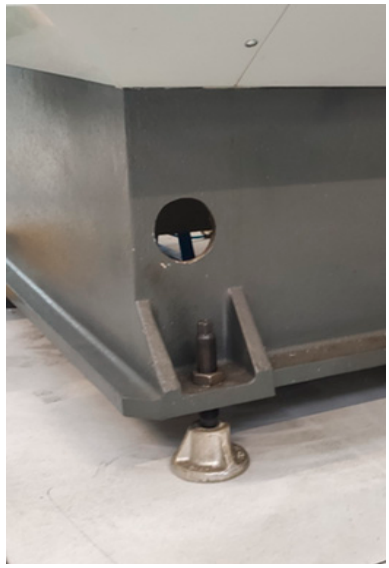

(a)

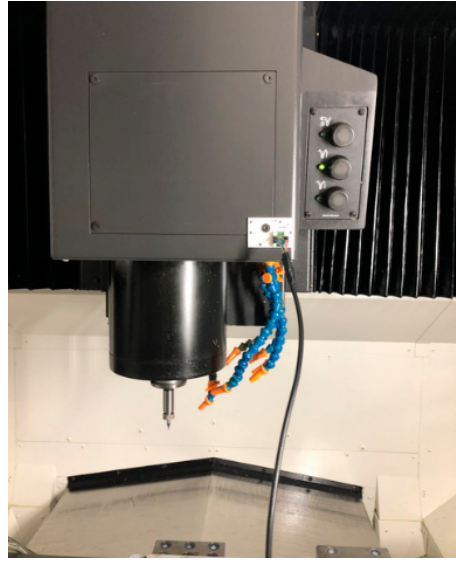

(b)

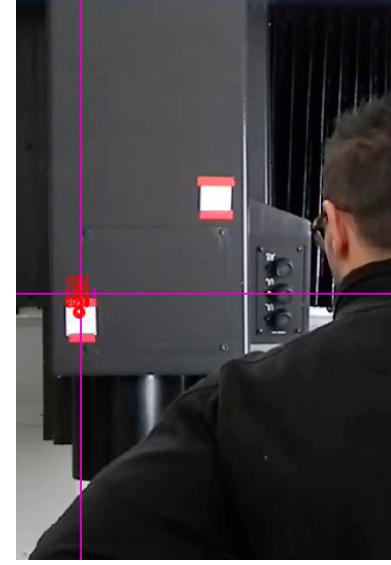

(c)

Figure 8. OKUMA machinery center: (a) detail of the typical base restraint (foundation washer) and (b) its spindle (in evidence, the mp\#1 accelerometer), with (c) example of video-tracking acquisition of the vertical displacements.

More in detail, four different working programs of the OKUMA center (W\#n) were examined, see Table 3. The acceleration histories corresponding to three of them (W\#1, W\#2, W\#3) are shown in Figure 9. To facilitate the quantitative comparison of these records, a limited interval of machine activity ( $0.2 \mathrm{~s}$ ) is emphasized. Basically, the W\#1-to-W\#3 acceleration histories were found associated to limited acceleration peaks, in the order of $0.6 \mathrm{~m} / \mathrm{s}^{2}, 1.38 \mathrm{~m} / \mathrm{s}^{2}$ and $1.6 \mathrm{~m} / \mathrm{s}^{2}$ ) respectively. A variable frequency content was also observed for them, corresponding to $125 \mathrm{~Hz}, 250 \mathrm{~Hz}$, and $165 \mathrm{~Hz}$ for W\#1, W\#2 and W\#3. In terms of human perception, no discomfort was highlighted for these programs.

Table 3. Experimental investigation of the OKUMA machine (vertical acceleration programs, mp\#1 sensor).

\begin{tabular}{cccc}
\hline & \multicolumn{3}{c}{ Spindle Analysis (mp\#1 Sensor) } \\
\hline W\#n & Records & Acceleration Peak $\left(\mathbf{m} / \mathbf{s}^{\mathbf{2}}\right)$ & Frequency $\mathbf{( H z})$ \\
\hline 1 & 3 & 0.6 & 125 \\
2 & 3 & 1.38 & 250 \\
3 & 3 & 1.6 & 165 \\
4 & 9 & 4.95 & 0.9 \\
\hline
\end{tabular}




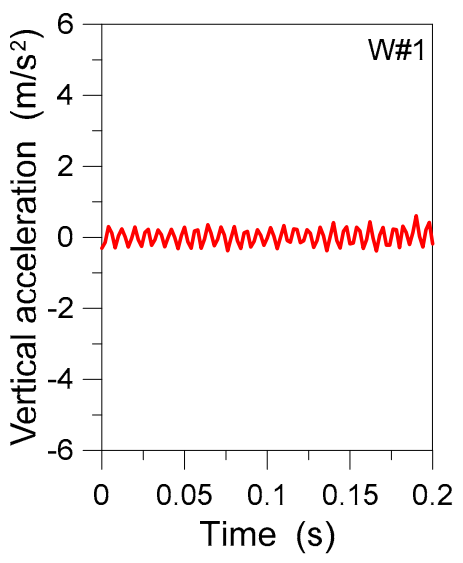

(a)

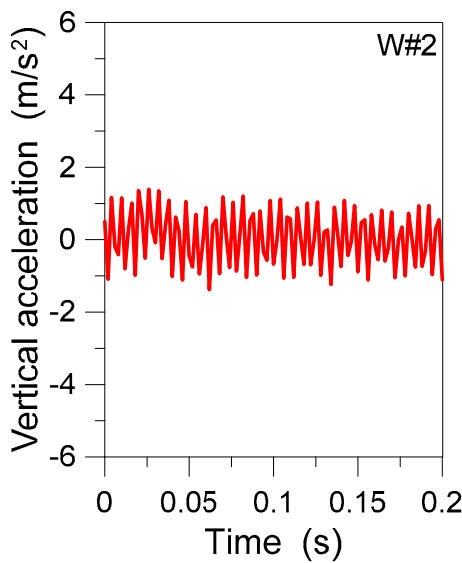

(b)

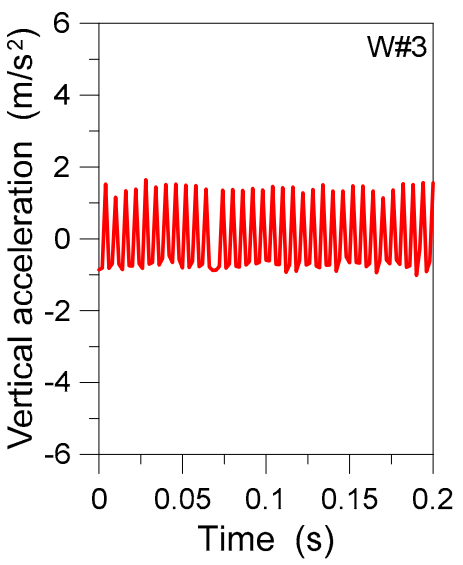

(c)

Figure 9. Experimental records of the spindle vertical acceleration from three different working activities of the OKUMA machinery center (mp\#1): (a) W\#1, (b) W\#2, and (c) W\#3.

From the detailed analysis of each process, more in detail, some irregularities were occasionally observed for the W\#3 program. This resulted in severe acceleration peaks that are proposed in Figure 10. In any case, their frequency content and number of repetitions was associated to secondary effects for the primary structure.

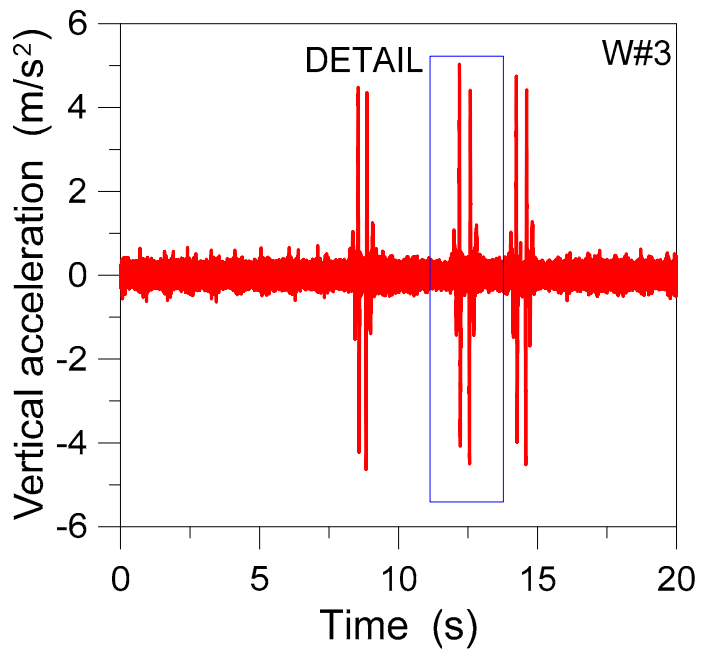

(a)

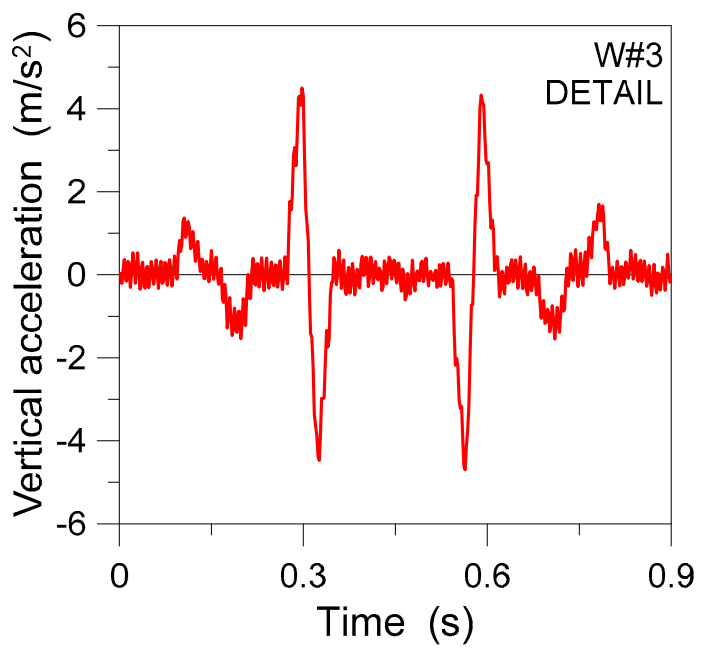

(b)

Figure 10. W\#3 process for the OKUMA machinery center (mp\#1): (a) experimental record of the spindle vertical acceleration, with $(\mathbf{b})$ detail view.

Among the available programs of the OKUMA center, the worst condition for the inter-story floor and the factory as a whole was in fact detected in the W\#4 process, whose acceleration history is shown in Figure 11a. Compared to Figure 9, as shown, the W\#4 process typically resulted in acceleration peaks in the order of $5 \mathrm{~m} / \mathrm{s}^{2}$, with a frequency of $0.9 \mathrm{~Hz}$. Given the severity of these accelerations and the general discomfort for the building occupants, moreover, the W\#4 experimental characterization was based on acceleration records based on a limited number of cycles for each test repetition (eight in total). Figure $11 \mathrm{~b}$ shows the synthetized signal that was experimentally derived to describe a possible continuous activity of the OKUMA. 


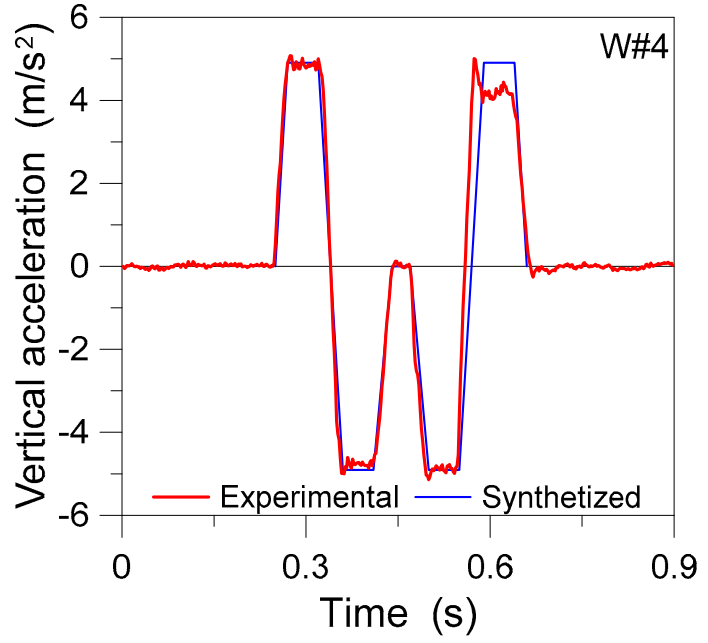

(a)

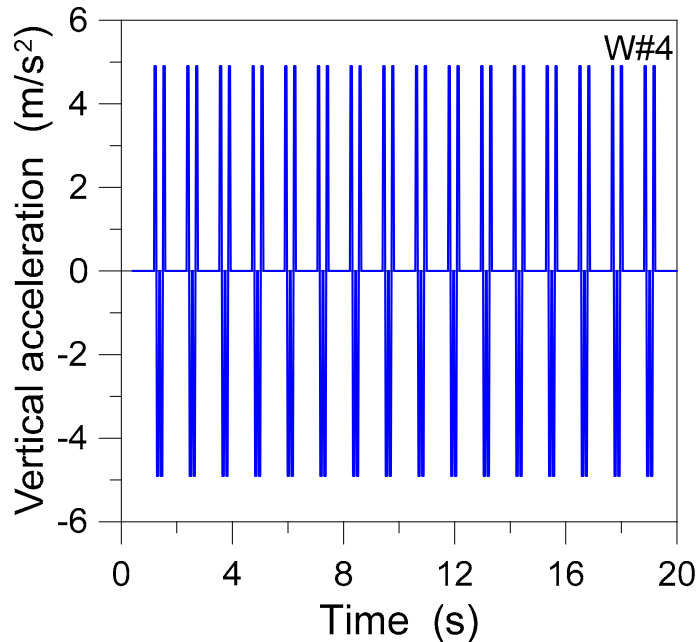

(b)

Figure 11. W\#4 process for the OKUMA machinery center (mp\#1): (a) experimental record of the spindle vertical acceleration (single cycle) and (b) derivation of the corresponding synthetized signal for a continuous activity.

\subsection{Analysis of the Inter-Story Floor}

In parallel to the machine testing described in Section 4.1, additional experimental records were collected on the inter-story floor, with an additional tri-axial MEMS accelerometer (ADXL355 type) that was variably positioned at the base of the OKUMA machine (mp\#2), as well as on the floor (s\#n). A detailed setup of instruments is shown in Figure 12.

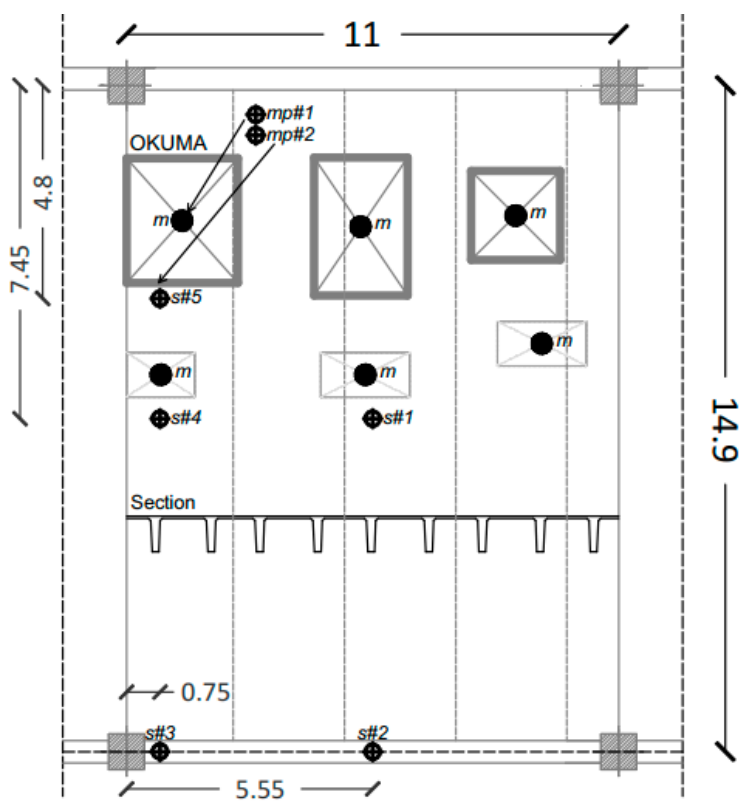

(a)

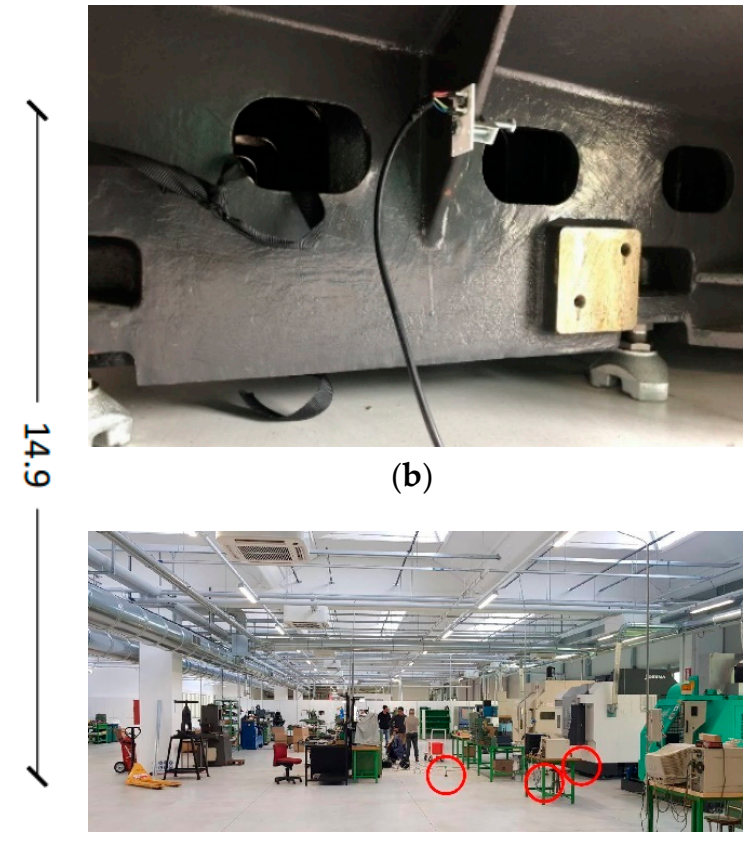

(c)

Figure 12. Reference setup for the field dynamic experiments: (a) plan view, with dimensions in m; (b) detail of mp\#2 (base of the machine frame); and (c) global view of the examined floor region

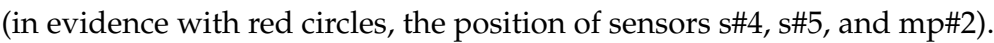


In doing so, a multitude of setup configurations were separately explored. Some of the sensor positions in Figure 12a were used for noise measurements only (i.e., s\#1, s\#2, and s\#3). Based also on Section 4.1, for the research purposes of this paper, a major attention was spent for the W\#4 program in Figure 11. Table 4 summarizes the setup configurations that were used for the FE assessment and validation of the coupled experimental-numerical procedure. The selected field experimental records, as shown, were further assessed towards the acceleration measurements of the so-called W\#0 program. In that case, the effects of a single in-place jump by a technician in position s\#4 (with all the machines at rest) were separately analyzed.

Table 4. Experimental investigation of the floor under the OKUMA activity (vertical acceleration programs, various acquisition sensors)

\begin{tabular}{cccc}
\hline \multirow{2}{*}{ W\#n } & \multicolumn{3}{c}{ Floor Analysis } \\
\cline { 2 - 4 } & Sensor & Records & Acceleration Peak $\left(\mathbf{m} / \mathbf{s}^{\mathbf{2}}\right)$ \\
\hline $0^{*}$ & $\mathrm{~s} \# 4$ & 5 & 0.26 \\
4 & $\mathrm{mp \# 2}$ & 3 & 0.52 \\
4 & $\mathrm{~s} \# 4$ & 3 & 0.28 \\
4 & $\mathrm{~s} \# 5$ & 3 & 0.21 \\
\hline * $=$ in-place jump of a technician in position s\#4 (with all the machines at rest).
\end{tabular}

From the collected experimental measurements, the time-acceleration and the corresponding power spectral density (PSD) functions were thus investigated.

Figure 13 shows the typical floor response under the $\mathrm{W} \# 0$ condition. From Figure $13 \mathrm{~b}$, it is possible to detect the two low fundamental natural frequencies of the floor, in the order of $f_{1, \exp }=7.4 \mathrm{~Hz}$ and $f_{2, \exp }=9.4 \mathrm{~Hz}$ respectively. Higher vibration frequencies can be also perceived in the range from $\approx 12 \mathrm{~Hz}$ to $\approx 40 \mathrm{~Hz}$.

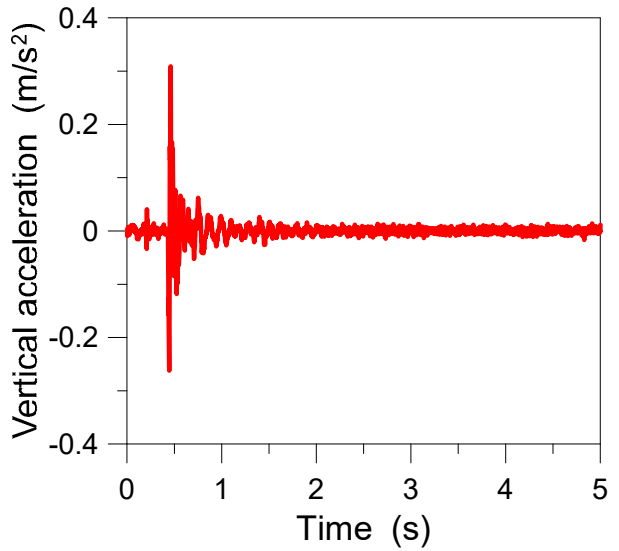

(a)

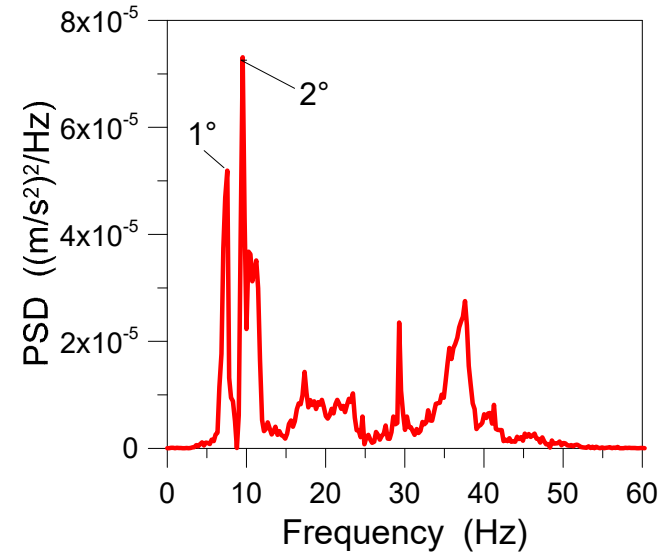

(b)

Figure 13. Experimental records for the inter-story floor region with the OKUMA at rest (W\#0). Measured (a) vertical acceleration and (b) corresponding power spectral density (PSD). In evidence, a selection of $5 \mathrm{~s}$ of acquisition (data from sensor s\#4).

In terms of quantification of the resonance effects due to the OKUMA; however, the attention was focused both on the magnitude of vibrations and their transmissibility to the primary structure. This was made possible by the availability of sensors for the acquisition of accelerations on the machine (base of the machine frame, mp\#2) and also in different regions of the floor (especially s\#4 and s\#5, according to Table 4).

Compared to the mp\#2 records on the machinery frame, for example, a rather good correlation was generally found with the content of the s\#5 and s\#4 records on the slab, as also expected due to 
the presence of rigid foundation restraints. Figure 14, however, shows the progressive increase of the measured PSD magnitude for the W\#4 program, as far as the sensors' location moves from the OKUMA center towards the mid-span region of the floor. The low natural frequencies in this case are even more pronounced than in Figure 13, due to the imposed vibrations. As far as the OKUMA machine operates as in $\mathrm{W} \# 4$, compared to $\mathrm{W} \# 0$, more pronounced resonance effects can be perceived in the form of a $\times 100$ PSD amplitude increase for the records in Figure 14, compared to Figure 13b.

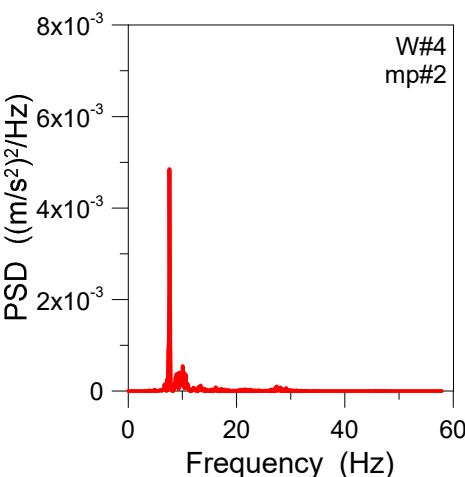

(a)

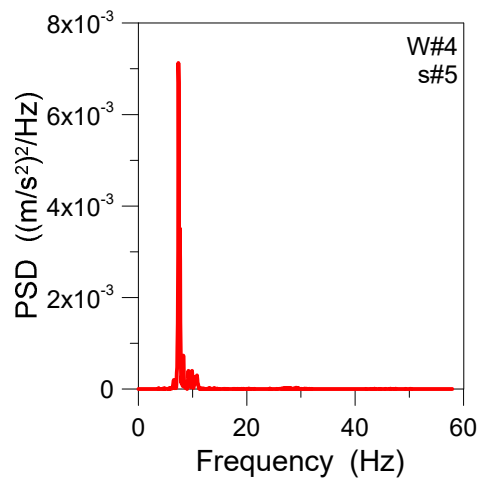

(b)

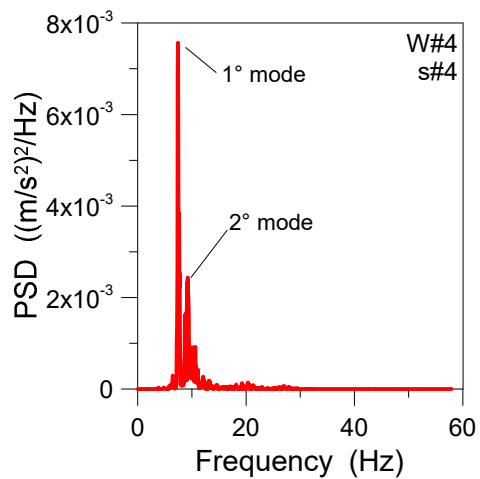

(c)

Figure 14. Experimental PSD for the examined floor region (W\#4), as obtained from (a) mp\#2 (base of the machine frame), (b) s\#5 (floor), and (c) s\#4 records (floor mid-span). In evidence, a selection of $5 \mathrm{~s}$ of acquisition.

The maximum resonance effects, in this regard, were generally measured in the mid-span region of the slab, rather than in the machinery region. The corresponding vertical accelerations are proposed in Figure 15, with evidence of $5 \mathrm{~s}$ of acquisitions for the W\#4 process. For the s\#4 control point in Figure 15, the effects of continuous machinery cycles can be perceived in vertical acceleration peaks in the order of $0.26 \mathrm{~m} / \mathrm{s}^{2}$.

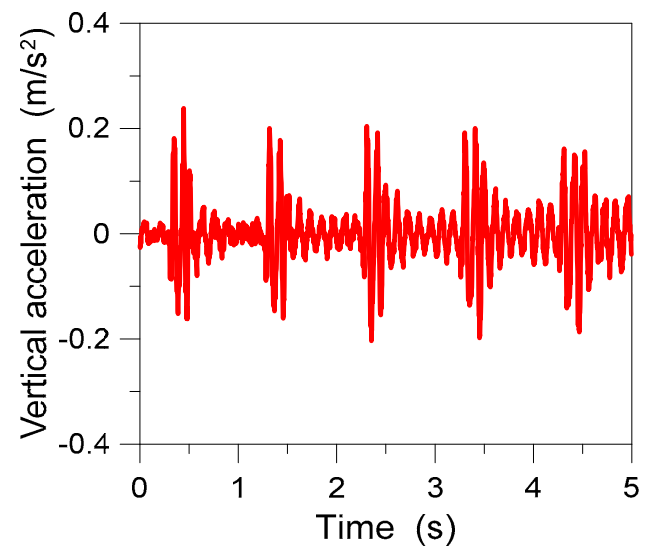

Figure 15. Experimental acceleration for the examined floor region (W\#4), as obtained from s\#4 records (floor mid-span). In evidence, a selection of $5 \mathrm{~s}$ of acquisition.

\subsection{Damping}

As a further attempt of interpretation of the experimental results, finally, the available records were used to calculated the damping parameter $\xi$ for the floor object of study. The total damping contribution, as known, results from a combination of structural damping (i.e., materials) but is also affected by finishing and equipment details, as well as foundation and soil parameters. According to [2], for open-plan concrete floors, the minimum conventional damping should be taken into account in the order of $\xi=2-3 \%$. In this paper, the logarithmic decrement method was applied to the collected 
experimental time histories. The total damping term was indirectly estimated in an average value of $\xi_{\exp } \approx 7.5 \%$ (and a maximum of $\xi_{\exp } \approx 9 \%$ ) for the floor under the W\#4 program (s\#4 data). A close correlation was found with the measured damping in $s \# 4$, with the machines at rest (W\#0 setup). Close to the OKUMA footprint, finally, the calculated damping resulted in a mean $\xi_{\exp } \approx 4-5 \%$ value (W\#4, s\#5 control point).

\section{Numerical Analysis}

The analysis was carried out in ABAQUS [30], based on a geometrically simplified but accurate FE model, that was earlier validated to capture the vibration response of the inter-story floor. Based on preliminary sensitivity analyses on full-size FE floor assemblies with different levels of detailing and computational cost, the selected region in Figure 5 was only described, with appropriate boundaries. Most of the results summarized in the following sections are thus referred to the so-labeled 'one-bay' numerical model of the structure $\left(l_{\mathrm{x}} \times l_{\mathrm{y}}\right.$ its size), that was preliminary validated in its basic input features, under static loading conditions.

\subsection{Description of Floor and Machines}

S4R shell elements were used for the double tee modules (Figure 16). In the case of the webs, $0.1 \mathrm{~m}$ high shell elements with average thickness were used (Figure 16a), while the slab was described with S4R elements and offset (Figure 16b). A variable shell thickness was used along the span $(0.2 \mathrm{~m}$ long segments), to account for the nominal geometry of the slab. The upward bow of precast modules was disregarded, and a distributed tie constraint was used between the precast and cast-in-situ shell elements (Figure 16a,b).

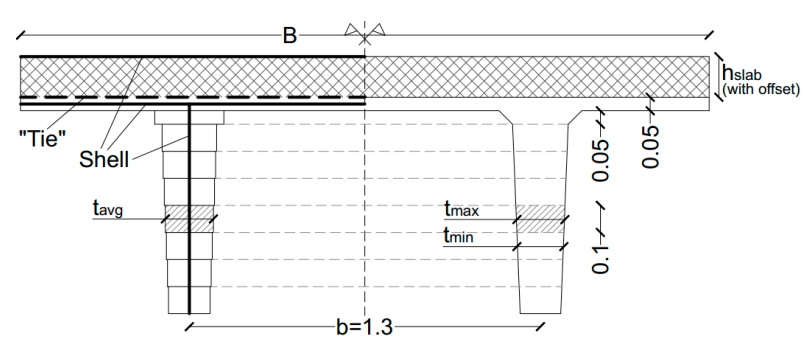

(a)

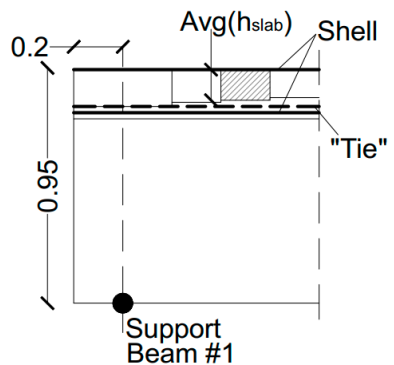

(b)

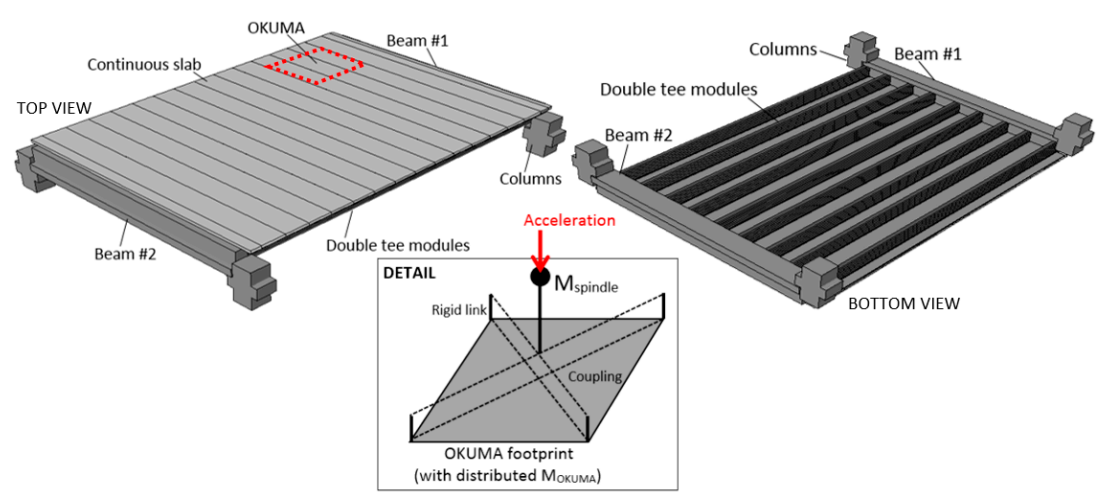

(c)

Figure 16. Modeling approach for the FE model of the inter-story floor region (ABAQUS, one-bay FE model): (a) cross-section and (b) side view details for a modular unit, with (c) final assembly (dimensions in $\mathrm{m}$ ). 
The floor region of interest was thus assembled through adjacent precast modules and a continuous slab, but also including the supporting beams and columns (Figure 16c). Three dimensional (3D) solid brick elements were used for them, to account for their geometry (and thus restraint effect for the floor). The final FE assembly resulted in 15,000 elements and 145,000 degrees of freedom (DOFs). Each precast web was thus locally restrained to the beams ('shell-to-solid' constraint). Additional boundaries were defined along the edges of the slab, due to continuity. Finally, two linear constitutive laws were used for the concrete materials in use, with mean nominal values for the dynamic MoE. According to technical documents of literature (i.e., [2]), its value was calculated as

$$
E_{\mathrm{cm}, \mathrm{dyn}} \approx 1.1 E_{\mathrm{cm}}
$$

Regarding the machines, a mixed modeling approach was taken into account for the OKUMA or for the MATSUURA and BRIDGEPORT centers respectively. A series of distributed masses was first used to reproduce the actual position of all the supported weights (i.e., based on the $m$ lumped terms in Figure 12, that were distributed over the footprint of each machine). In the case of the OKUMA machine only, see the detail in Figure 16c, an additional lumped mass $M_{\text {spindle }}$ was used to account for the spindle movements. The experimental history of machinery accelerations (i.e., Figures 9 and 11) was assigned to the $M_{\text {spindle }}$ lumped mass, and thus transferred to the floor. In doing so, a special attention was paid for the schematization of the machinery effects. A rigid link was first introduced to connect $M_{\text {spindle }}$ with the floor. To this aim, an intermediate 'RP' node in Figure 16c was positioned in the center of mass of the OKUMA footprint. This RP was set as reference node for an additional 'coupling' kinematic constraint, that was used to connect the RP node (and thus $\mathrm{M}_{\text {spindle }}$ ) to a set of four base rigid links, that were used to schematically describe the OKUMA foundation restraints (washers) in Figure $8 \mathrm{a}$ and to transfer the machine acceleration to the slab.

Such a series of FE modeling assumptions, in accordance with Figure 2a, was chosen to maximize the computational efficiency of the FE models, but at the same time to reproduce the presence of rigid restraints $\left(K_{1}=\infty\right)$ for the undamped OKUMA machine $\left(C_{1}=0\right)$. On the other side, the inter-story floor was numerically described with detailed geometrical and mechanical properties, so as to capture its stiffness $K_{2}$, mass $M_{2}$, and damping $C_{2}$. Following Section 4.3, all the dissipative capacities were lumped on the floor slab (uniform modal damping).

\subsection{Static Analysis}

A preliminary static analysis was carried out to assess the bending response of the one-bay model under the effects of a static peak force derived from the OKUMA activities. As far as FOKUMA is in fact calculated from the acceleration peaks in Figures 9 and 11 and the available mass contributions for the machine, the corresponding mid-span deflection can be calculated with the available tools.

At first, assuming that the OKUMA is mounted on the middle axis of the hosting module $(B=2.38 \mathrm{~m})$, the deflection is the same of a simply supported composite beam (double tee + slab), with $a, b$ the distance of the force introduction from the ends

$$
u_{\max }^{\text {stat }}=\frac{1}{3} \frac{F_{\mathrm{OKUMA}} a^{2} b^{2}}{(E I)_{\mathrm{comp}} l_{\mathrm{y}}}
$$

with $(E I)_{\text {comp }}$ the bending stiffness of the composite resisting section, as obtained from Table 1. Both Equation (8) and the corresponding numerical analysis resulted in a maximum static deflection in the order of $0.029 \mathrm{~mm}$ (W\#4 process).

For the OKUMA machine in the actual position, otherwise, the static deformed shape was found

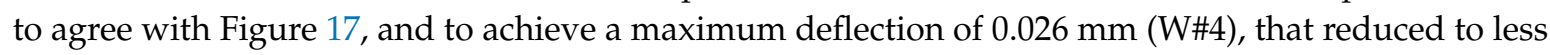
than $0.01 \mathrm{~mm}$ for the other low-amplitude programs (W\#1-to-W\#3). 

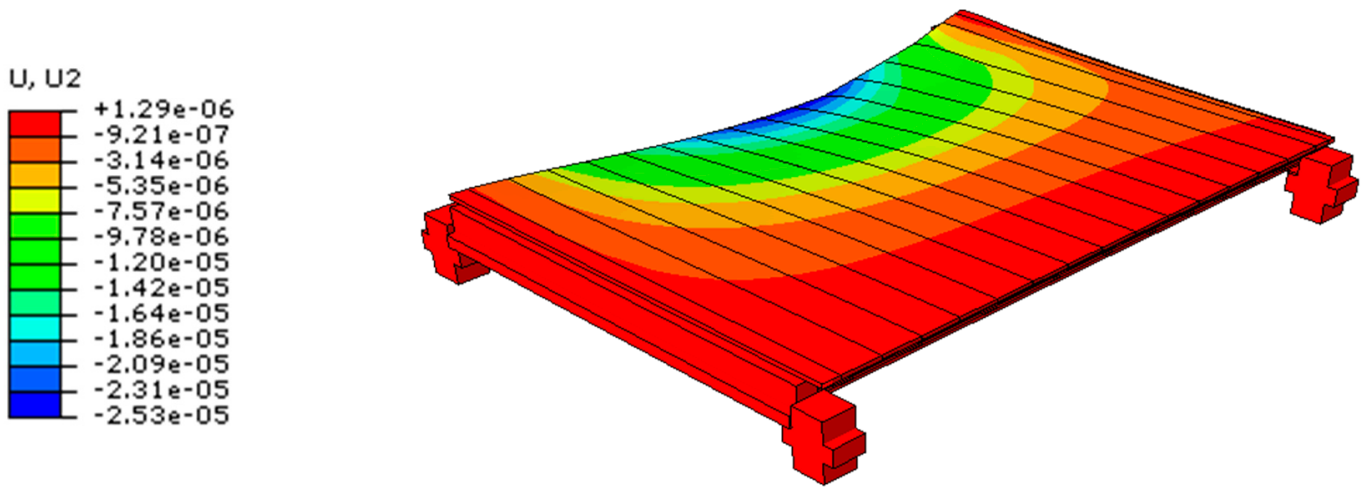

Figure 17. Deflection of the floor under the equivalent static force peak of the OKUMA machine (ABAQUS, one-bay FE model, W\#4, legend values in $\mathrm{m}$, scale factor: $\times 50,000$ ).

\subsection{Natural Frequency Results}

A linear 'frequency' analysis was carried out on the floor region with a series of masses distributed as in Figure 12 (machines at rest). Based on the available experimental feedback (Section 4), the attention was focused on the two first vibration modes of the system.

According to the test observations, the analysis was in fact intended to capture all the relevant structural phenomena in the range up to $10 \mathrm{~Hz}$, so that they could be assessed towards the few available experimental data. The so-collected shapes are proposed in Figure 18, with evidence of the corresponding natural frequencies.

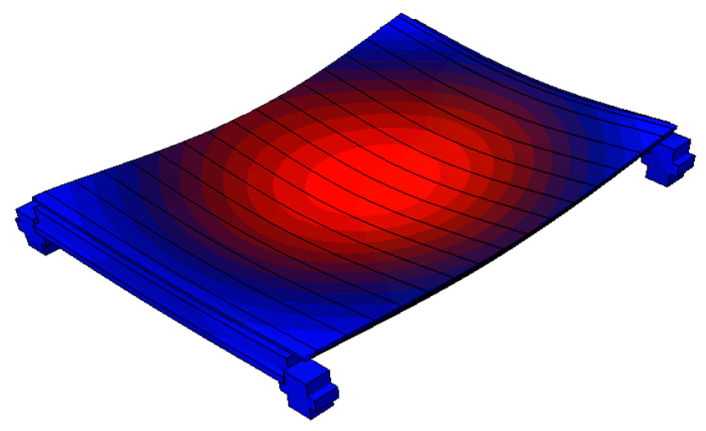

(a)

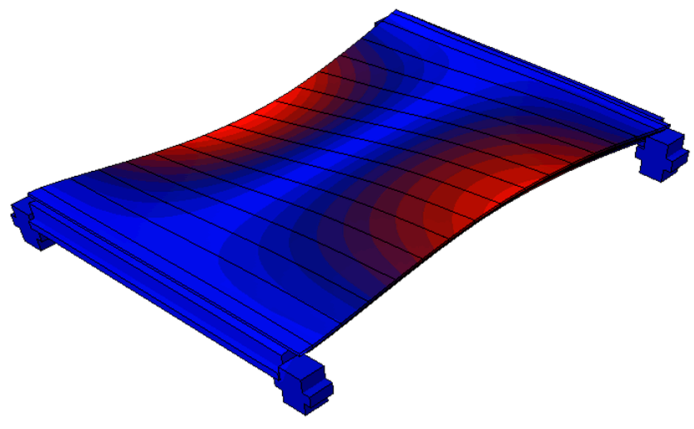

(b)

Figure 18. Numerical vibration modes of the inter-story floor region with all the $\mathrm{CNC}$ machines at rest (ABAQUS 'frequency' analysis, one-bay FE model). (a) $f_{1}=7.37 \mathrm{~Hz}$. (b) $f_{2}=9.41 \mathrm{~Hz}$

Worth of interest in Figure 18 is especially the second mode in the range of $\approx 9.4 \mathrm{~Hz}$, given that it is characterized by large vertical deformations in the region of the OKUMA machinery center, and thus involving a torsional deformation for the supporting modular units. As also expected, anyway, both the FE vibration shapes in Figure 18 were found associated to global bending deformations of a unidirectionally stiffened plate ('joist panel mode') with flexible girders, for the floor as a whole. Accordingly, the early stage of the research study was spent for the reliability analysis of the FE approach herein proposed, that was finally preferred to a full-size FE model of the floor for both its computational efficiency and accuracy. At the same time, it is also recognized that the FE model in Figure 16 can capture the plate vibrations of the selected floor region only, while it could unavoidably lose additional relevant vibration frequencies for the entire floor in Figure 5.

In this regard, the FE investigation for the one-bay model was further assessed towards the experimental frequencies but also towards different numerical models of the structure, having a different level of accuracy and computational cost. In Table 5, in this regard, some of so-collected numerical 
outcomes are reported, where the mode order $n$ is referred to the experimental predictions for the floor region of interest.

Based on the schematic drawing in Figure 6, the fundamental natural frequency is first roughly estimated for a single concrete module (with $B=2.38 \mathrm{~m}$, for the module hosting the OKUMA). Following classical literature formulations, it is in fact assumed that the vibration response of the beam-like modular unit can be described as [31]

$$
\frac{\partial^{2}}{\partial x^{2}} E I(x)\left(\frac{\partial^{2} u(x, t)}{\partial x^{2}}\right)+\rho A \frac{\partial^{2} u(x, t)}{\partial t^{2}}=0
$$

and thus (simply supported end sections)

$$
f_{1, \text { an }}=\frac{\pi}{2 L^{2}} \sqrt{\frac{E I}{\rho A}}
$$

with $u(x, t)$ the vertical displacement, at a given abscissa $x(0 \leq x \leq L)$ and time instant $t$; while $E$ and $\rho$ in Equation (10) denote the MoE and density of concrete, $I$ is the second moment of area and $A$ the cross-section for the schematic drawing in Figure $6 \mathrm{a}$ (with $\rho=2500 \mathrm{~kg} / \mathrm{m}^{3}$ ). As far the slab in the top is fully disregarded (in the same way of the supported CNC machines and equipment), and the mean dynamic MoE is derived from Equation (7), Equation (10) would result in a fundamental frequency $f_{1, \text { an }}=7.79 \mathrm{~Hz}$ that roughly capture the experimental prediction from Figure 18.

On the other side, given the $5 \%$ of scatter for the prediction from Equation (10) and the experimental frequency $f_{1, \exp }$ of the floor, the same model still suggests a prevailing 'joist panel mode' for the structure object of study. Moreover, the same prediction $f_{1, \text { an }}$ is still lower than $10 \mathrm{~Hz}$ (Figure 4) and thus would suggest the need of dedicated early-stage design considerations.

Additional comparative frequency estimates are thus proposed in Table 5, as obtained from FE models characterized by a progressive increase of their accuracy and computational cost. The first and simplest FE model, herein labeled as 'one-module' ( $B \times l_{\mathrm{y}}$ its size), is representative of a single double tee module $(B=2.38 \mathrm{~m})$, with the top slab and the supported OKUMA + equipment masses. The major limit of the 'one-module' model is that the adjacent modules are disregarded, in the same way of the flexibility of the end restraints. Ideal simply supports are in fact used to restraint the webs, in place of the actual precast beams.

As a further elaboration of the 'one-bay' model, finally, the ' $2 \times 2$-bay' model in Table 5 is still numerically described and assembled with the same approach described in Figure 16, but includes a wide region of floor $\left(2 l_{\mathrm{x}} \times 2 l_{\mathrm{y}}\right.$ its size $)$ and the slab continuity in both the $x$ and $y$ directions, thus resulting in 62,000 elements and 390,000 DOFs.

Table 5. Comparison of natural vibration frequencies for the inter-story floor with non-operating CNC machines, based on different modeling approaches

\begin{tabular}{cccccc}
\hline & & & \multicolumn{3}{c}{ FE model } \\
\hline \multicolumn{2}{l}{ Experimental } & $\begin{array}{c}\text { Analytical } \\
\text { (Equation (10)) }\end{array}$ & 1-Module & One-Bay & 2 $\times$ 2-Bay \\
\hline$n$ & $f(\mathbf{H z})$ & $f(\mathbf{H z})$ & $f(\mathbf{H z})$ & $f(\mathbf{H z})$ & $f(\mathbf{H z})$ \\
\hline 1 & 7.40 & 7.79 & 7.39 & 7.37 & 7.38 \\
- & - & - & - & - & 7.61 \\
- & - & - & - & - & 8.17 \\
2 & 9.40 & - & - & 9.41 & 9.42 \\
\hline
\end{tabular}

As far as the complexity and detailing of the FE assembly increases, the rather close correlation for the fundamental mode predictions can be noticed in Table 5 . On the other side, a number of additional vibration modes can be also noticed for the $2 \times 2$-bay model, given that the stiffened plate bending 
deformation of the floor as a whole can separately affect single bays of the diaphragm. In this research study, for example, it was proved that the intermediate frequencies in Table 5 are still associated with global bending deformations for the examined inter-story floor, but with negligible vertical displacements for the region object of study. The vibration shapes in Figure 19, finally, further confirm the good correlation of the one-bay and $2 \times 2$-bay models, with regard to the floor region of interest. As such, the one-bay assembly was still found reliable for the purpose of this investigation.

Worth noting in Figure 19a,b is the good correlation of the first two numerical frequencies with the experimental derivations. The frequency scatter was calculated in less than $0.5 \%$ for them. On the other side, given the lack of multiple simultaneous accelerometers on the floor, the FE validation was still limited to the lowest frequency estimates, rather than the corresponding normalized modal shapes. In Figure 19c, finally, two intermediate numerical vibration modes are also proposed, with evidence of mostly null deformations for the floor region object of study.

Moreover, the FE analysis further confirmed the marked effects due to both the magnitude and position of the non-operating machines. Focusing on the first and second experimental modes only, for example, the total masses of the non-operating machines for the FE assemblies in Figures 18 and 19 were found responsible of a $-6.5 \%$ frequency decrease (with $f_{1 \text {,empty }}=7.81 \mathrm{~Hz}$ and $f_{2 \text {,empty }}=9.98 \mathrm{~Hz}$ for the empty floor, based on the one-bay model predictions), thus resulting in even more pronounced serviceability issues (i.e., increased flexibility, and thus sensitivity to vibrations).

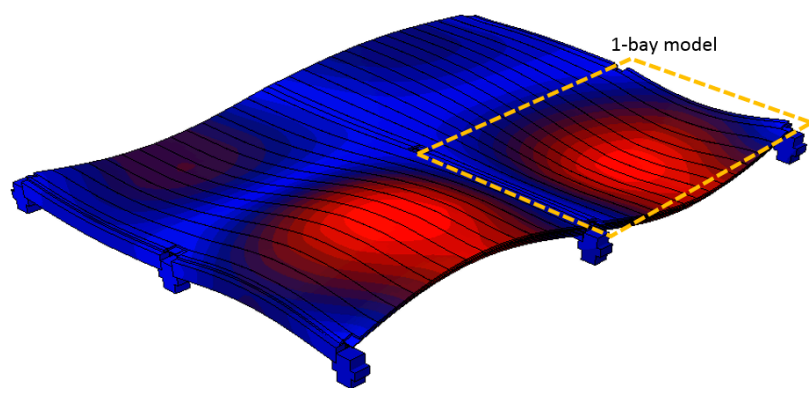

(a)

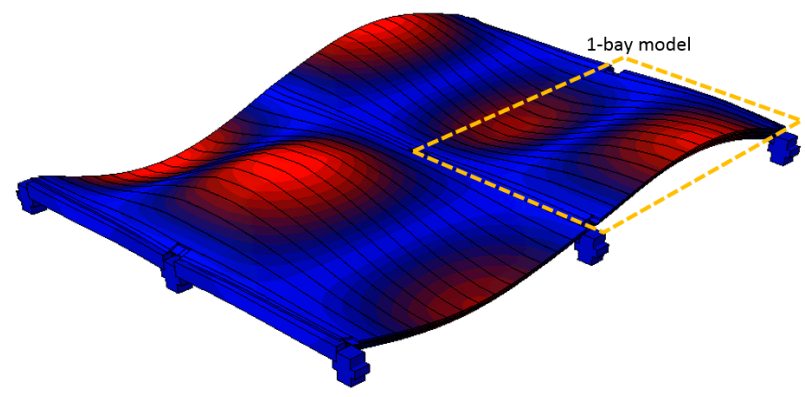

(b)

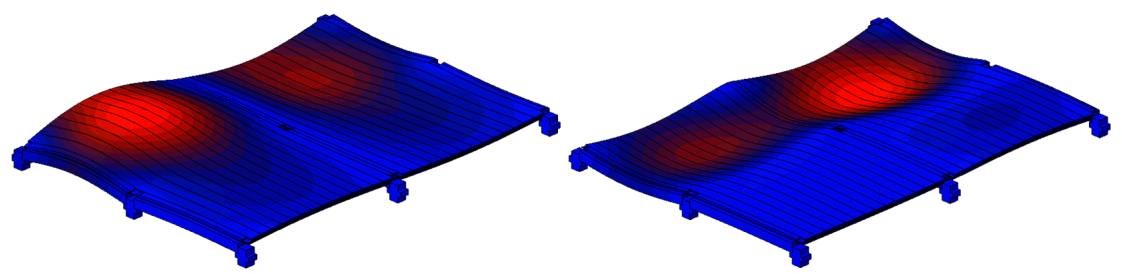

(c)

Figure 19. Fundamental natural vibration modes with all the CNC machines at rest (ABAQUS 'frequency' analysis, $2 \times 2$-bay model): (a) $\mathrm{f}_{1}=7.38 \mathrm{~Hz},(\mathbf{b}) \mathrm{f}_{2}=9.42 \mathrm{~Hz}$, and (c) intermediate modes. 


\section{Coupled Experimental-Numerical Vibration Assessment}

Linear steady state dynamics (SSD) analyses were carried out on the one-bay FE assembly of Figure 16, with the operative OKUMA machine. While the numerical study was extended to all the available W\#n working programs, the attention was focused on the W\#4 condition. Based on the schematic approach of Figure 16c, the SSD analysis was thus set in the range of 1-10 Hz, including the input vibration modes of Figure 18 as a reference.

\subsection{Experimental Configuration}

First, the SSD analysis was carried out on the one-bay assembly under the W\#4 setup, that was found critical for the real structure. Later on, the working programs W\#1, W\#2, and W\#3 were also taken into account, for comparative numerical purposes. The same solving approach was considered, while the input spindle acceleration history was described as in Figure 9 or Figure 11 for each process. In doing so, the dynamic MoE of concrete was estimated from the available experimental properties (Table 2). In the same way, a total damping $\xi_{\exp }=9 \%$ was taken into account for the analyses, based on the experimental feedback (Section 4.3).

Major FE outcomes and selected SSD results are proposed in Figures 20 and 21. More in detail, the estimated SSD acceleration an velocity of the floor are shown in Figure 20 as a function of the frequency of the system, with a focus on the $\$ \# 1$ and s\#4 numerical estimates, compared to the s\#4 experimental peak (Table 4). The confirmation that the structure suffers for marked resonance issues in the w\#4 setup is worth noting, as it can be noticed in Figure 20a for the range of the examined $f_{1}-f_{2}$ natural frequencies. Moreover, the s\#4 control point and the second mode of vibration of the structure were usually found to be associated with more pronounced dynamic effects (i.e., acceleration peaks), compared to the central s\#1 point, as an effect of the machine-induced vibrations and the related torsional deformations of the deck.

For the FE model under the experimental setup, see Figure 20a, the acceleration peak for the floor was calculated in the order of $\approx 0.3 \mathrm{~m} / \mathrm{s}^{2}$. For the same W\#4 loading scheme, moreover, non-null vertical acceleration records were numerically predicted for the control points s\#2 and s\#3, as a direct effect of the intrinsic flexibility of the supporting precast beams, thus confirming the potential (compared to ideal rigid boundaries) of refined FE models for vibration assessment purposes.

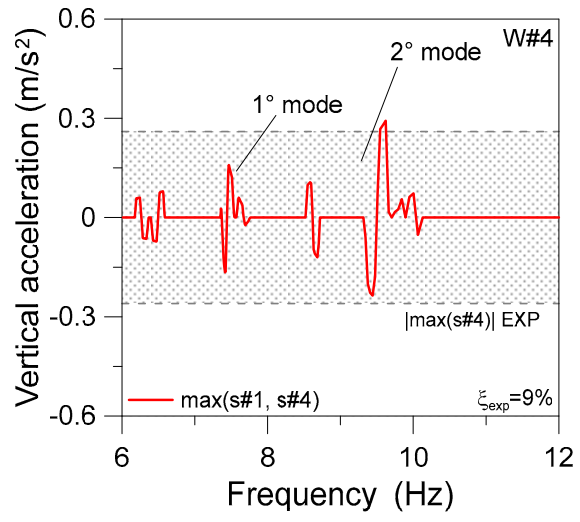

(a)

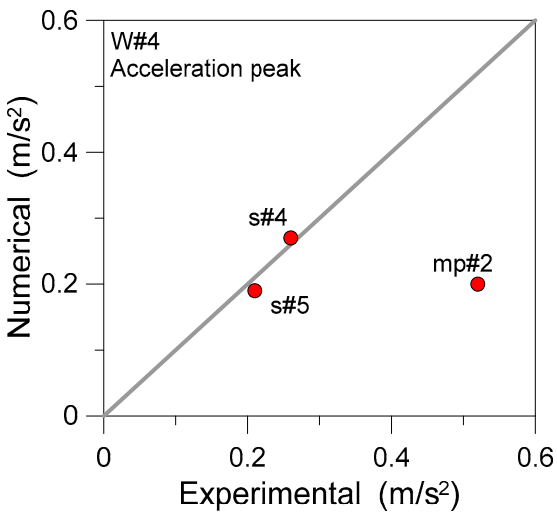

(b)

Figure 20. SSD analysis of the inter-story floor region with the working OKUMA (ABAQUS, one-bay FE model, W\#4). Evolution of (a) vertical acceleration peaks in the s\#1 and s\#4 control points, with (b) comparison of absolute acceleration peaks experimental configuration (synthetized signal, experimental dynamic MoE for concrete and $\xi_{\exp }=9 \%$ ).

Figure 20b shows the experimental and FE numerical acceleration peaks from the same SSD analysis, as far as the s\#4, s\#5, and $\mathrm{mp \# 2}$ control point are taken into account. It is possible to see a rather close correlation of measurements on the side of the floor, while the rigid link-based mechanical 
system in of Figure 16 tends to underestimate the corresponding experimental measurement, due to the lack of detailing on the side of machinery components.

The refined structural FE model of the floor was used for additional comparative studies and vibration serviceability analyses. In this regard, Figure 21 shows that the velocity peaks for the W\#2 program (in the frequency domain) are remarkably lower than the limit value of $20 \mathrm{~mm} / \mathrm{s}$ recommended in [42].

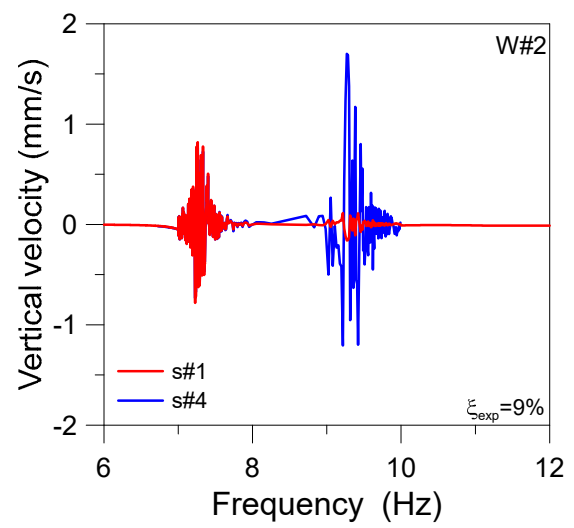

Figure 21. SSD analysis of the inter-story floor region with the working OKUMA (ABAQUS, one-bay FE model, W\#2). Evolution of vertical velocity peaks in the s\#1 and s\#4 control points. Experimental configuration (synthetized signal, experimental dynamic MoE for concrete and $\xi_{\text {exp }}=9 \%$ ).

The velocity peak for the floor under the W\#4 process (Figure 22), in this regard, was numerically predicted in $\approx 6-7 \mathrm{~mm} / \mathrm{s}$, thus still far away from the reference limit of $20 \mathrm{~mm} / \mathrm{s}$ (and thus ensuring possible structural damage for the floor) but remarkably higher, compared to the other $\mathrm{W} \# n$ configurations.

Finally, Figure 22c shows the maximum dynamic deflection for the FE model under the various working programs. Compared to the static deflection of the floor (Section 5.2), these dynamic estimates resulted in a DAF in the order of +3.1 for the $\mathrm{W} \# 4$ process, or DAF $=+1.6$ for the low-amplitude W\#1-to-W\#3 programs). It is interesting to notice that no discomfort was claimed by the client and by the factory workers, while most of the issues were confirmed to derive from the $\mathrm{W \#} 4$ activities.

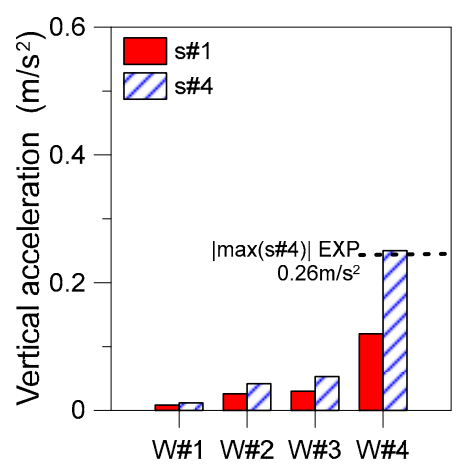

(a)

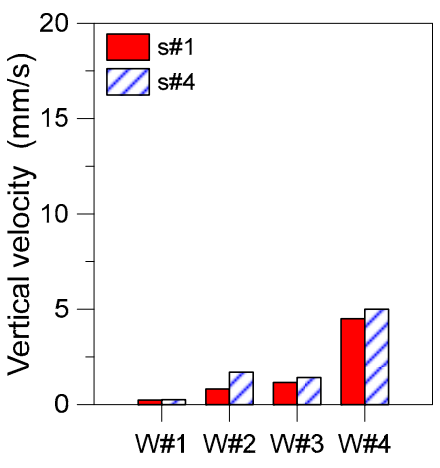

(b)

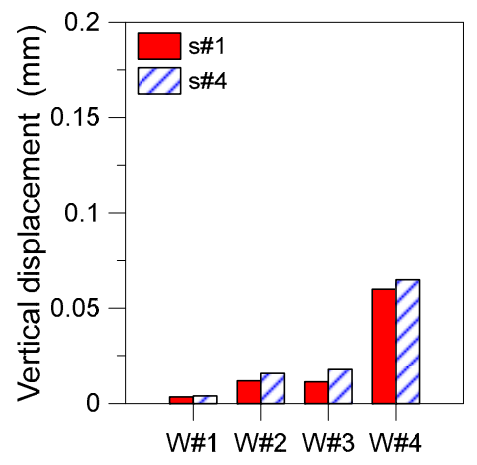

(c)

Figure 22. SSD analysis of the inter-story floor region with the working OKUMA (ABAQUS, one-bay FE model): (a) vertical acceleration, (b) velocity, and (c) displacement peaks in the s\#1 and s\#4 control points. Experimental configuration (synthetized signal, experimental dynamic MoE for concrete and experimental damping $\xi_{\exp }=9 \%$ ). 


\subsection{Design Configuration}

In conclusion, the attention was still focused on the analysis of resonance effects of the one-bay model, but under a typical design configuration (i.e., by taking into account the nominal material properties, as well as the conventional damping of the structure). The dynamic effects are collected in Figure 23, for all the available working processes of the OKUMA center.

Compared to Section 6.1, such a series of FE estimates represents the numerical feedback in support of the early design stage of the factory, and thus an important outcome that suggests the predictivity of possible vibration issues. The dynamic MoE of concrete, in this regard, was found to slightly affect the corresponding SSD predictions and absolute peaks. On the other side, the maximum sensitivity of FE predictions derived from the reference modal damping of the system. An example is shown in Figure 24 for the W\#4 process only, where the 'experimental' and 'design' modeling assumptions for the floor are compared. As also emphasized in Section 6.1 for the dynamic response for the W\#1-to-W\#3 programs, the corresponding 'design' scenarios resulted in relatively low peaks. In contrary, the W\#4 estimates were found to roughly approach the reference velocity limit of $20 \mathrm{~mm} / \mathrm{s}$ for structural damage prevention, thus representing a potential early warning for the overall design process. From the vertical displacements in Figure 23c, more in detail, the corresponding DAF was calculated in a mean value of +2.8 for the W\#1-to-W\#3 conditions, and up to +6.2 for the W\#4 program.

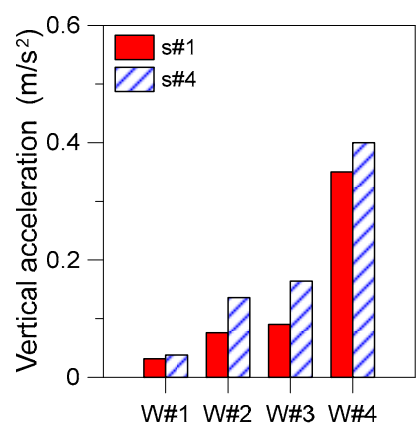

(a)

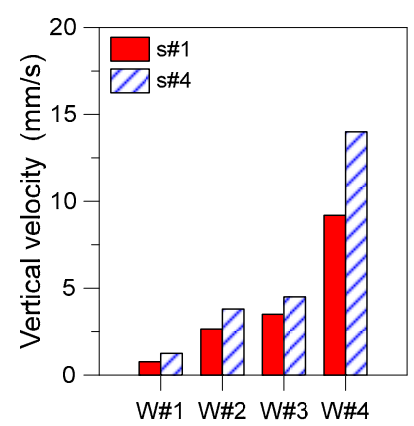

(b)

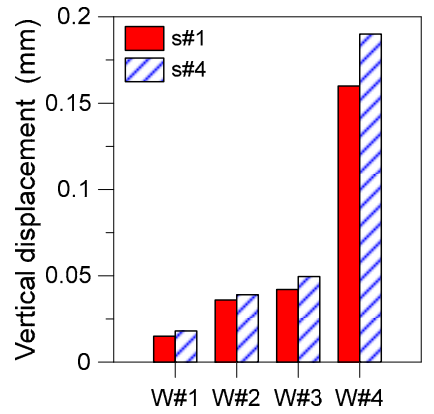

(c)

Figure 23. SSD analysis of the inter-story floor region with the working OKUMA (ABAQUS, one-bay FE model): (a) vertical acceleration, (b) velocity, and (c) displacement peaks in the s\#1 and s\#4 control points. Design configuration, with synthetized signal, nominal dynamic MoE for concrete and conventional damping $\xi=3 \%)$.

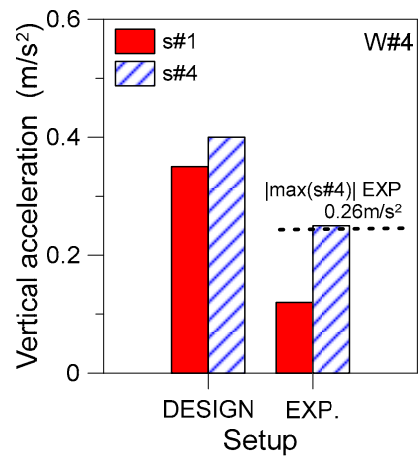

(a)

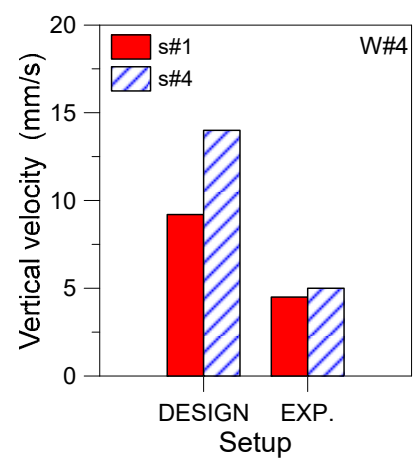

(b)

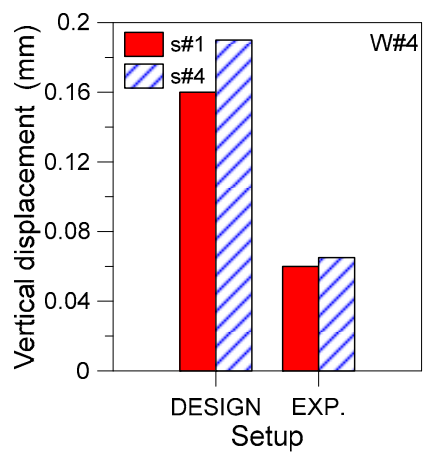

(c)

Figure 24. SSD analysis of the inter-story floor region with the working OKUMA (ABAQUS, one-bay FE model, W\#4): (a) vertical acceleration, (b) velocity, and (c) displacement peaks in the s\#1 and s\#4 control points, as a function of the dynamic MoE of concrete and damping. 


\section{Conclusions}

The prediction of machine-induced vibrations, as known, is a key step for the early design stage of industrial buildings and infrastructures. Similarly, the machine-structure interaction is a demanding aspect that requires computationally efficient but reliable computational tools. However, the description of the vibration source (i.e., machine-induced signal), as well as the calibration of the available structural models and details, can be both uncertain. In common practice, the vibration serviceability of flexible load-bearing structures is generally assessed with the support of simplified models and conventional input features, especially in terms of machinery characterization, materials stiffness, and damping.

In this paper, a coupled experimental-numerical approach was presented and validated for the vibration serviceability assessment of machine-induced vibrations. To this aim, a case-study eyewear factory was investigated, with a focus on the vibration issues of its inter-story floor, where several non-isolated CNC machines were mounted. The factory was built in Italy 2019, but started to suffer for marked resonance issues, due to the lack of communication between the client and the structural designer, hence resulting in the presence of heavy non-isolated machinery centers mounted on its flexible, long-span inter-story floor. In the last years, several research projects have been dedicated to the analysis of machines on rigid foundations, as well as to the experimental monitoring of machinery components, for maintenance and optimal productivity purposes. Besides, most of the available studies are focused on separate aspects only (i.e., structural or mechanical for the machines), as well as on specific case-study issues.

The attention of the research study herein presented was thus first focused on the experimental characterization of the machinery activities (i.e., movable components) under various working programs of technical interest. A single MEMS accelerometer was used to capture and properly describe (with the derivation of a synthetized signal) the actual input vibration source. In parallel, the experimental investigation was also extended to the inter-story floor, giving evidence of the transmissibility of machine-induced vibrations. The available experimental feedback was used to integrate and validate a reliable and computationally efficient one-bay finite element (FE) model of the structure. The latter, as shown, can represent an efficient tool for floors that are characterized by a 'joist panel' vibration (i.e., with a fundamental natural frequency that is close to the frequency of the joists in bending about their major axis). Based on the comparative studies summarized in the paper, the potential of coupled experimental-numerical predictive studies was thus emphasized, giving evidence of the feasible prevention (or possible mitigation) of severe troubles due to machine-induced vibrations.

Author Contributions: This research paper results from a joint collaboration of all the involved authors. E.B. and M.F. handled the field experimental analysis and post-processing stage, while C.B. took care of the numerical analysis. All the authors contributed to the discussion and analysis of comparative results, and thus to the drafting and review of the final paper. All authors have read and agreed to the published version of the manuscript.

Funding: This research received no external funding.

Conflicts of Interest: The authors declare no conflict of interest.

\section{References}

1. Bachmann, H.; Ammann, W. Vibrations in Structures Induced by Man and Machines; IABSE-International Association for Bridge and Structural Engineering: Zurich, Switzerland, 1987; ISBN 3-85748-052-X.

2. Feldmann, M.; Heinemeyer, C.; Butz, C.; Caetano, E.; Cunha, A.; Galanti, F.; Goldack, A.; Hechler, O.; Hicks, S.; Keil, A.; et al. Design of Floor Structures for Human Induced Vibrations; Technical Report EUR 24084 EN.; Publications Office of the European Union: Bruxelles, Belgium, 2009; ISBN 978-92-79-14094-5. [CrossRef]

3. Da Silva, J.G.S.; Sieira, A.C.C.F.; Da Silva, L.A.P.S.; Rimola, B.D. Dynamic Analysis of Steel Platforms When Subjected to Mechanical Equipment-Induced Vibrations. J. Civ. Eng. Arch. 2016, 10, 1103-1113. [CrossRef]

4. Brownjohn, J.; Pavic, A. Vibration control of ultra-sensitive facilities. Proc. Inst. Civ. Eng. Struct. Build. 2006, 159, 295-306. [CrossRef] 
5. Chang, M.-L.; Lin, C.-C.; Ueng, J.-M.; Hsieh, K.-H.; Wang, J.-F. Experimental study on adjustable tuned mass damper to reduce floor vibration due to machinery. Struct. Control Health Monit. 2009, 17, 352-548. [CrossRef]

6. Kazantzi, A.K.; Vamvatsikos, D. Seismic and Vibration Performance Rehabilitation for an Industrial Steel Building. Pr. Period. Struct. Des. Constr. 2020, 25, 05020001. [CrossRef]

7. Wilson, R.R. Machine Foundations. In Vibrations of Engineering Structures; Lecture Notes in Engineering; Springer: Berlin/Heidelberg, Germany, 1985; Volume 10. [CrossRef]

8. Tian, Y.; Liu, Z.; Xu, X.; Wang, G.; Li, Q.; Zhou, Y.; Cheng, J. Systematic review of research relating to heavy-duty machine tool foundation systems. Adv. Mech. Eng. 2019, 11. [CrossRef]

9. Stimac, G.; Braut, S.; Zigulic, R. Structural optimization of turbine generator foundation with frequency constraint. Strojarstvo 2011, 53, 389-398.

10. Liu, J.B.; Wang, Z.Y.; Zhang, K.F.; Pei, Y.X. 3D Finite element analysis of large dynamic machine foundation considering soil-structure interaction. Eng. Mech. 2002, 19, 34-35.

11. Tian, Y.; Shu, Q.; Liu, Z.; Ji, Y. Vibration Characteristics of Heavy-Duty CNC Machine Tool-Foundation Systems. Shock. Vib. 2018, 2018, 1-12. [CrossRef]

12. Werner, U. Derivation of a plane vibration model for electrical machines on soft machine foundations. Forsch. Ing. 2010, 74, 185-205. [CrossRef]

13. Lipus, J.; Jankovych, R.; Hammer, M.; Lipus, T. Vibration and related diagnostics of motors and generators. MM Sci. J. 2016, 2016, 1639-1642. [CrossRef]

14. Janak, L.; Stetina, J.; Fiala, Z.; Hadas, Z. Quantities and sensors for machine tool spindle condition monitoring. MM Sci. J. 2016, 2016, 1648-1653. [CrossRef]

15. Cizikova, A.; Monkova, K.; Monka, P.; Moravec, M. Analysis of frequency characteristics at spindle of CNC machining centre. MM Sci. J. 2016, 2016, 1515-1518. [CrossRef]

16. Abdulhani, F.; Alswede, J. Study of vibration for CNC machine at different feed. Int. J. Adv. Res. Technol. 2014, 3, 21-29.

17. Dogrusoz, H.; Wszołek, G.; Czop, P.; Słoniewski, J. Vibration monitoring of CNC machinery using MEMS sensors. J. Vibroengineering 2020, 22, 735-750. [CrossRef]

18. Ford, D.; Myers, A.; Haase, F.; Lockwood, S.; Longstaff, A. Active vibration control for a CNC milling machine. Proc. Inst. Mech. Eng. Part C J. Mech. Eng. Sci. 2013, 228, 230-245. [CrossRef]

19. Elfatah, S.A. Practical Design and Construction of Machine Foundations Subjected to Impact Loads. Pr. Period. Struct. Des. Constr. 2020, 25, 04020008. [CrossRef]

20. Yung, G. Dynamic Analysis of Machine Foundation: When a Static Force cannot give the full picture. In Proceedings of the HKIE-IEM-CIE Tripartite Seminar-Recent Developments in Limit State Design for Geotechnical Works, Hong Kong, China, 28 November 2014.

21. Okpala, C.C. Shop floor vibration analysis and control. Int. J. Adv. Eng. Technol. 2016, 7, 207-211.

22. Vlad, I. Machine Foundations and Blast Engineering Vibrations Case Studies. In Proceedings of the International Conferences on Recent Advances in Geotechnical Earthquake Engineering and Soil Dynamics, San Diego, CA, USA, 27 May 2010; Volume 7.

23. Józwik, J.; Wac-Włodarczyk, A.; Michałowska, J.; Kłoczko, E.M. Monitoring of the Noise Emitted by Machine Tools in Industrial Conditions. J. Ecol. Eng. 2018, 19, 83-93. [CrossRef]

24. Pinnington, R.; White, R. Power flow through machine isolators to resonant and non-resonant beams. J. Sound Vib. 1981, 75, 179-197. [CrossRef]

25. Lau, M.; Fok, S.; Seet, G.; Low, E. The Control of Vibration Transmission from an Engine to its Resonant Base Structure. J. Mar. Sci. Res. Dev. 2011, 2. [CrossRef]

26. Wigaard, J.; Hoen, C.; Fredo, C.R. Designing structural damping to avoid resonance problems in structures, piping and subsea equipment: Risk reduction and fatigue life improvement. In Proceedings of the OMAE2005-24th International Conference on Offshore Mechanics and Arctic Engineering, Halkidiki, Greece, 12-17 June 2005.

27. Seidlitz, S.; Kuether, R.J.; Allen, M.S. Experimental Approach to Compare Noise Floors of Various Torsional Vibration Sensors. Exp. Tech. 2016, 40, 661-675. [CrossRef]

28. Goyal, D.; Pabla, B. Development of non-contact structural health monitoring system for machine tools. J. Appl. Res. Technol. 2016, 14, 245-258. [CrossRef] 
29. Dekýš, V.; Sapietová, A.; Stevka, O. Understanding of the Dynamical Properties of Machines Based on the Interpretation of Spectral Measurements and FRF. Appl. Mech. Mater. 2013, 486, 106-112. [CrossRef]

30. ABAQUS Computer Software; Simulia: Providence, RI, USA, 2020.

31. Clough, R.W.; Penzien, J. Dynamics of Structures; McGraw-Hill: New York, NY, USA, 1993; ISBN 0-07-011394-7.

32. Pap, Z.B.; Kollár, L.P. Dynamic Response of Long Rectangular Floors Subjected to Periodic Force Excitation. Materiral 2019, 12, 1417. [CrossRef]

33. Nayak, A.N.; Satpathy, L.; Tripathy, P.K. Free vibration characteristics of stiffened plates. Int. J. Adv. Struct. Eng. 2018, 10, 153-167. [CrossRef]

34. Srivastava, A.K.L. Vibration of stiffened plates with cut-out subjected to partial edge loading. J. Inst. Eng. Ser. A 2012, 93, 129-135. [CrossRef]

35. Srivastava, A.; Pandey, S.; Kumar, A. Dynamical Analysis of Stiffened Plates under Patch Loading. Int. J. Appl. Mech. Eng. 2013, 18, 537-553. [CrossRef]

36. Guo, T.; Cao, Z.; Zhang, Z.; Li, A. Frequency domain-based analysis of floor vibrations using the dynamic stiffness matrix method. J. Vib. Control 2018, 25, 763-776. [CrossRef]

37. Allen, D.E.; Murray, T.M. Design criterion for vibrations due to walking. Eng. J. 1993, 30, 117-129.

38. Eurocodice 4-Progettazione Delle Strutture Composte Acciaio-Calcestruzzo-Parte 1-1: Regole Generali e Regole per Gli Edifici; UNI EN 1994-1-1:2004; Ente Nazionale Italiano di Unificazione (UNI): Milan, Italy, 2005.

39. Ministero delle Infrastrutture e dei Trasporti-DM 17/01/2018. Norme Tecniche per le Costruzioni (NTC2018); Ministero delle Infrastrutture e dei Trasporti: Rome, Italy, 2018.

40. Ministero delle Infrastrutture e dei Trasporti-Circolare n.7 del 21/01/2019—Istruzioni per l'applicazione dell' "Aggiornamento delle Norme Tecniche per le Costruzioni"; Ministero delle Infrastrutture e dei Trasporti: Rome, Italy, 2019.

41. Shahabpoor, E.; Pavic, A.; Racic, V. Interaction between Walking Humans and Structures in Vertical Direction: A Literature Review. Shock. Vib. 2016, 2016, 1-22. [CrossRef]

42. Criteri di Misura e Valutazione Degli Effetti Delle Vibrazioni Sugli Edifici; UNI9916: 2014; Ente Nazionale Italiano di Unificazione (UNI): Milan, Italy, 2014.

43. Structural Vibration-Part 1: Prediction of Vibration Parameters, 2001; DIN4150: 2001; Deutsches Institut für Normung E.V. (DIN): Berlin, Germany, 2001.

44. OKUMA Europe GmbH. Available online: www.okuma.eu (accessed on 27 July 2020).

45. MATSUURA Machinery Corporation. Available online: https://www.matsuura.co.jp/english/ (accessed on 27 July 2020).

46. BRIDGEPORT Machines. Available online: https://www.hardinge.com/product-brand/bridgeport/ (accessed on 27 July 2020).

47. Bedon, C.; Bergamo, E.; Izzi, M.; Noé, S. Prototyping and Validation of MEMS Accelerometers for Structural Health Monitoring-The Case Study of the Pietratagliata Cable-Stayed Bridge. J. Sens. Actuator Netw. 2018, 7, 30. [CrossRef]

48. Tracker-Video Analysis and Modeling Tool. 2020. Available online: http://physlets.org/tracker (accessed on 27 July 2020).

(C) 2020 by the authors. Licensee MDPI, Basel, Switzerland. This article is an open access article distributed under the terms and conditions of the Creative Commons Attribution (CC BY) license (http://creativecommons.org/licenses/by/4.0/). 